\title{
Article
}

\section{A bird's eye view of NK cell receptor interactions with their MHC class I ligands}

Saunders, Philippa M., Vivian, Julian P., O'Connor, Geraldine, Sullivan, Lucy C., Pymm, Phillip, Rossjohn, Jamie and Brooks, Andrew G.

Available at http://clok.uclan.ac.uk/25537/

Saunders, Philippa M., Vivian, Julian P., O'Connor, Geraldine ORCID: 00000002-7440-162X, Sullivan, Lucy C., Pymm, Phillip, Rossjohn, Jamie and Brooks, Andrew G. (2015) A bird's eye view of NK cell receptor interactions with their MHC class I ligands. Immunological Reviews, 267 (1). pp. 148-166. ISSN 0105-2896

It is advisable to refer to the publisher's version if you intend to cite from the work. http://dx.doi.org/10.1111/imr.12319

For more information about UCLan's research in this area go to

http://www.uclan.ac.uk/researchgroups/ and search for <name of research Group>.

For information about Research generally at UCLan please go to http://www.uclan.ac.uk/research/

All outputs in CLoK are protected by Intellectual Property Rights law, including Copyright law. Copyright, IPR and Moral Rights for the works on this site are retained by the individual authors and/or other copyright owners. Terms and conditions for use of this material are defined in the policies page.

\section{CLoK}

Central Lancashire online Knowledge www.clok.uclan.ac.uk

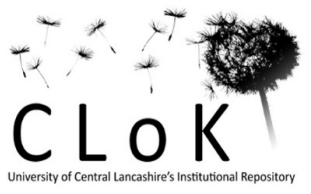




\section{A bird's eye view of NK cell receptor interactions with their MHC class I ligands}

Philippa M. Saunders ${ }^{1}$, Julian P. Vivian ${ }^{2,3}$, Geraldine M. O’Connor ${ }^{1}$, Lucy C. Sullivan ${ }^{1}$, Philip Pymm $^{2,3}$, Jamie Rossjohn ${ }^{2,3,4^{*}}$ and Andrew G. Brooks ${ }^{1 *}$

${ }^{1}$ Department of Microbiology and Immunology, The University of Melbourne at the Peter Doherty Institute for Infection and Immunity, 792 Elizabeth Street, Melbourne, VIC 3000, Australia

${ }^{2}$ Department of Biochemistry and Molecular Biology, School of Biomedical Sciences, Monash University, Clayton, Victoria 3800, Australia.

${ }^{3}$ ARC Centre of Excellence in Advanced Molecular Imaging, Monash University, Clayton, Victoria 3800, Australia

${ }^{4}$ Institute of Infection and Immunity, Cardiff University School of Medicine, Heath Park, Cardiff CF14 4XN, UK

*Correspondence to:

Andrew Brooks, e-mail: agbrooks@unimelb.edu.au

Jamie Rossjohn, e-mail: Jamie.rossjohn@ monash.edu

Keywords: Natural Killer cell receptors, Killer cell Immunoglobulin-like Receptors, Human Leukocyte Antigen, CD94-NKG2. 
Running title: NK cell recognition of HLA class I proteins

Key words: natural killer cell receptors, killer cell immunoglobulin like receptors, HLA, polymorphism

Summary

The surveillance of target cells by Natural Killer (NK) cells utilises an ensemble of inhibitory and activating receptors, many of which interact with major histocompatibility (MHC) class I molecules. NK cell recognition of MHC class I proteins is important developmentally for the acquisition of full NK cell effector capacity and during target cell recognition such that the engagement of inhibitory NK cell receptors and MHC class I molecules leads to the attenuation of NK cell activation. Human NK cells have evolved two broad strategies for recognition of human leukocyte antigen (HLA) class I molecules: 1) direct recognition of polymorphic classical HLA class I proteins by diverse receptor families such as the Killer cell Immunoglobulin-like Receptors (KIR); and 2) indirect recognition of conserved sets of HLA class I-derived peptides displayed on the non-classical HLA-E for recognition by CD94-NKG2 receptors. In this review, we assess the structural basis for the interaction between these NK receptors and their HLA class I ligands and, using the suite of published KIR and CD94-NKG2 ternary complexes, highlight the features that allow NK cells to orchestrate the recognition of a range of distinctly different HLA class I proteins. 


\section{Introduction}

NK cells express an array of receptors belonging to a number of distinct families that recognize classical and non-classical MHC class I molecules and MHC class I-like molecules, including MICA and -B and ULBPs (1). These recognition events are not only used to interrogate the health status of target cells but also play a developmental role by licensing NK cells that have inhibitory receptors binding self-MHC class I for the acquisition of full effector functions. In humans there are three "classical" MHC class I proteins, termed HLA-A, -B and -C, which display high degrees of polymorphism. The evolution of polymorphic HLA molecules has seen HLA-A and B allotypes accumulate variations within the antigen recognition site under pressure from $\mathrm{T}$ cell immunity, whilst HLA-C appears to have become specialized for NK cell immunity (2-4). While HLA polymorphism impacts peptide-loading and peptide repertoire to influence $\mathrm{T}$ cell receptor recognition (5), it also poses challenges for NK cell recognition of HLA class I molecules.

There are at least two clear strategies employed by germline-encoded NK cell receptors for recognition of classical HLA class I molecules. The first involves targeting conserved regions of the HLA that display little polymorphism. For example, the Leukocyte Immunoglobulin-like Receptors (LIR) interact with the conserved $\alpha 3$ domain of HLA class I molecules and the $\beta_{2} \mathrm{~m}$ subunit (6). The alternative molecular strategy for NK receptors involves recognition of the polymorphic regions of the HLA, which are in evolutionary terms, a moving target. Perhaps unsurprisingly therefore, the MHC class I-reactive receptors utilised by NK cells differ across evolution. Namely, the Ly49 receptors expressed by rodent NK cells are homodimeric type II integral membrane receptors that have a C-type lectin-like fold (7). In contrast, in primates, these same functions appear to be mediated by the KIR family, which are of type I topology and possess extracellular domains that utilise an Ig fold $(8,9)$. Despite the differences in structure and topology, both receptor families utilise similar signalling pathways with inhibitory receptors possessing immunoreceptor tyrosine-based inhibitory motifs (ITIM), allowing for the recruitment and activation of phosphatases such as SHP-1, and 
activating members associating with small immunoreceptor tyrosine-based activating motif (ITAM)containing adaptor proteins, including DAP12 (10-12). Furthermore, both KIR and Ly49 receptor families exhibit evidence of gene duplication, recombination and significant diversification that may be critical to retain the capacity to interact with the proteins encoded by highly polymorphic $M H C-I$ loci $(13,14)$.

Early studies showed that NK cell recognition of allogeneic target cells was dependent on HLA-C expression, with the HLA-C dimorphism (residues 77 and 80), which subdivide HLA-C molecules into $\mathrm{C} 1$ or $\mathrm{C} 2$ groupings, associated with protection from lysis by discrete subsets of NK cells (1518). Lanier, Parham and colleagues further identified a $70 \mathrm{kD}$ protein on a subset of NK cells, which recognised target cells expressing HLA-B allotypes with the Bw4 motif, a serological epitope spanning residues $77-83(19,20)$. Additionally, a third specificity was observed wherein a larger protein of $140 \mathrm{kDa}$, a disulfide linked dimer, had specificity for HLA-A3 and the closely related HLAA11 $(21,22)$. Together these studies identified four distinct groups of HLA class I allotypes that were capable of inhibiting NK cell activation. The receptors dictating this specificity were found to belong to a group of proteins, now known collectively as the KIRs.

\section{Killer cell Immunoglobulin-like Receptors}

Fifteen KIR genes have been identified in humans, encoded within the Leukocyte Receptor Cluster on chromosome 19 , two of which are pseudogenes $(23,24)$. Remarkable genetic diversity exists in the KIR loci with polymorphism in individual genes as well as haplotypic variation in the gene copy number, both of which result in significant differences between individuals in the repertoire of expressed KIRs (25). The KIR proteins possess either two or three extracellular immunoglobulin (Ig) domains (termed D0, D1 and D2) giving rise to the KIR2D or KIR3D nomenclature (Figure 1) (26). Moreover while the prototypical KIR delivers inhibitory signals via the recruitment of phosphatases to long, ITIM-containing cytoplasmic tails (11), activating KIR possess shorter cytoplasmic regions 
and a basic residue within their transmembrane region that facilitates their interaction with ITAMcontaining adaptors $(10,27,28)$. Thus inhibitory KIR and activating KIR are termed L and S, respectively, in reference to the length of their cytoplasmic region, and hence signalling potential.

\section{Common features of KIR-HLA interactions}

To date, the structure of seven KIRs (2DL1, 2DL2, 2DS2, 2DL3, 2DL4, 2DS4 and 3DL1) (29-37) have been determined either in isolation or in complex with a HLA class I protein (Figure 2A-F). Each of the KIR ternary complexes shows the KIR positioned over the HLA class I molecule in a similar manner (Figure 2). Namely, the D1 and D2 domains form a V-shaped interface, binding in an orthogonal manner with respect to the peptide-binding groove, positioning the D1 and D2 domains over the $\alpha 1$ and $\alpha 2$ helices of HLA, respectively. In addition to contacting the HLA class I molecule, the KIR is also situated over the C-terminal region of the peptide, indicative of peptide-dependent modulation of KIR interactions $(29-31,33)$.

Analysis of the available KIR crystal structures shows the D1 and D2 domains to be arranged with slightly different hinge angles, some of which may alter upon complexation with the HLA class I ligand. In addition the hinge region also twists about the D1/D2 axis, thereby subtly impacting on the KIR-peptide(p)-HLA interface (Figure 2G-H). Regardless of hinge flexibility, common to the KIRpHLA complexes, is a well-conserved binding footprint spanning residues 145 to 151 on the $\alpha 2$ helix of the HLA that interacts with the D2 domain of the KIR (Figure 3A-D and Table 1). Strictly conserved across all KIR structures is (i) a salt bridge between Arg145 and an aspartate (Asp135 KIR2D; Asp 230, KIR3DL1) (29-31, 33); and (ii) a H-bond between Arg145 and a serine (Ser133, KIR2D; Ser228, KIR3DL1) (29-31, 33). Mostly conserved are the contacts to Ala149, Ala150, Lys146 and Arg151 of the HLA (29-31,33). Accordingly, the region between residues 145 and 151 on the $\alpha 2$ helix provides a conserved platform for KIR docking. 
In contrast, the interactions between the D1 domain of the KIR and residues on the $\alpha 1$ helix of HLA class I are more variable and are primarily responsible for determining the specificity of individual KIR (discussed below) (Figure 4A-H). Notably, the C1/C2 determinants, and the Bw4 motif, are found within the region of the D1 contact zone. Moreover, within this region, the highly conserved HLA class I residues, Glu72, Arg75, Arg79 and Tyr84, can make variable contacts to the different KIR (29-31, 33). The polymorphic positions 76,80 and 83 are of particular importance to establishing the molecular architecture of the HLA that enables each KIR to distinguish between distinct but structurally related ligands.

\section{KIR2DL recognition of HLA-C}

The structure of KIR2DL2 bound to HLA-C*03:04 (HLA-C1) (29) was the first KIR/HLA class I complex determined and when compared with the KIR2DL1-HLA-C*04:01 complex (HLA-C2) (30) allowed the molecular details underpinning the discrimination between KIR2DL1/2 for HLA-C1 and $\mathrm{C} 2$ to be ascertained. In comparison to KIR2DL1, the D1 domain of KIR2DL2 sits more to the Nterminus of the $\alpha 1$ helix and forms more extensive and varied contacts (Figure 3) (29, 30). Notably, of the contacts made to the $\alpha 1$ helix, only those involving Phe45 on the D1 domain are maintained in both KIR2DL1 and KIR2DL2 (Table 1).

Of the 16 residues in KIR2DL2 that contacted HLA-C*03:04, only two residues, positions 44 and 70, differed in the C2-reactive KIR2DL1. Here, Met70 of KIR2DL2 made extensive contacts to the HLA class I $\alpha 1$ helix whilst the equivalent Thr70 of KIR2DL1 did not contact the HLA (Table 1, Figure 4A,B) $(29,30)$. While mutagenesis studies suggested residue 70 did not play a major role in defining KIR2DL receptor specificity, position 44 is of central importance $(29,38)$. Notably, Met44 of KIR2DL1, and the neighbouring residues create a negatively charged "specificity" pocket to accommodate the characteristic Lys80 of C2 allotypes (30) (Figure 4C,D). In comparison, Lys44 of KIR2DL2 constitutes the primary stabilising contact between KIR2DL2 and Asn80 of the HLA-C1 
allotype. Indeed, the substitution of Lys44 in KIR2DL2 for its methionine counterpart in KIR2DL1 abrogated binding to $\mathrm{C} 1$ and was sufficient to convert the specificity of the mutant KIR2DL2 to C2 $(29,38)$. The reciprocal Met44 mutation to lysine similarly converted the specificity of KIR2DL1 (38). Residue 44 of both KIR2DL1 and KIR2DL2 contacts residue 80, the dimorphic position that distinguishes HLA-C1 (asparagine) from HLA-C2 (lysine). Thus, the specificity of KIR2DL1 and KIR2DL2 for HLA-C1 and C2 groups hinges on position 44 of the KIR molecule.

Although there is little evidence that KIR2DL1 can bind $\mathrm{C} 1$ allotypes or that these allotypes can confer protection from lysis by NK cells expressing KIR2DL1, a number of studies have demonstrated that KIR2DL2, and its allelic variant KIR2DL3, can interact with C2 allotypes. KIR2DL2-Ig fusion proteins have been shown to bind beads coated with a number of C2 allotypes, albeit not to the extent that they bound C1 (39). Additionally, Pende and colleagues have shown that KIR2DL2/3 expression was sufficient to inhibit NK cell killing of both C2 positive leukemic blasts and 721.221 transfectants expressing C2 allotypes, suggesting that the low affinity KIR2DL2/3 recognition of $\mathrm{C} 1$ allotypes was not without functional relevance (40). It will be of interest to establish the molecular basis underpinning the extent of promiscuity of the KIR2DL2/3 alleles towards the C2 allotypes.

\section{KIR2DS recognition of HLA ligands}

While there is extensive functional, binding, mutagenesis and structural data probing the interactions of inhibitory KIR with their ligands, our understanding of activating KIR is less developed. Despite very high levels of sequence identify, binding studies have typically found that the activating KIR either do not interact with HLA class I or bind with considerably lower affinity than their inhibitory counterparts $(41,42)$. The structures of KIR2DL/HLA ternary complexes provided a general framework for understanding the KIR2DS molecules as a result of these high levels of sequence identity. Not surprisingly the structure of KIR2DS4 was highly similar to that of KIR2DL, although 
differences in some of the loop conformations between the 2DL/2DS4 structures provided an understanding of likely differences in ligand specificity $(29,37)$.

The determination of the structure of KIR2DS2 bound to HLA-A*11:01 offered insight into how activating receptors can dock with HLA class I molecules (31) (Figures 3B, 4E,F). The overall binding interface of the complex was appreciably smaller than that of both KIR2DL ternary complexes. The contacts between KIR2DS2 and the $\alpha 2$ helix were predominantly conserved with KIR2DL, thereby implicating the specificity of the KIR2DS2 interaction being attributable to the D1 contacts to the $\alpha 1$ helix (Figure 4E). Here, the D1 domain of KIR2DS2 docked more towards the Cterminus of the $\alpha 1$ helix than any KIR solved to date. Consequently, the contacts by KIR2DS 2 to the $\alpha 1$ helix were more limited and had lower shape complementarity compared to the KIR2DL ternary complexes. (29-31).

There are four amino acid differences between the extracellular domains of KIR2DS2 and KIR2DL2 (positions 16, 45, 148 and 200), of which position 45 interacts directly with the $\alpha 1$ helix. Tyr45 is proposed to determine the specificity of KIR2DS2 since the introduction of a tyrosine at position 45 of KIR2DL2 abrogated its capacity to bind HLA-Cw3 (43), whilst mutation of the Tyr45 in KIR2DS2 to phenylalanine conferred the capacity to bind HLA-Cw7 (42). Interestingly while only the hydroxyl group of the Tyr45 side-chain makes contact to the $\alpha 1$ helix, this interaction does not drive recognition of HLA-A*11:01, as the Tyr45Phe mutation still recognised HLA-A*11:01, albeit with reduced affinity (31). Thus, Tyr45 likely operates via a steric mechanism to orient the D1 domain onto the binding interface. This working model is supported by the observation that a Tyr45Ala mutant abrogated binding (31).

The observation that an activating KIR binds to common HLA-A allotypes (HLA-A*1101 and $\left.A^{*} 11: 02\right)$ that are expressed at high levels is intriguing. To date, there is limited functional evidence 
implicating KIR2DS2 recognition in NK cell activation, raising the possibility that the interaction is highly peptide dependent. Indeed, a better understanding of the significance of this KIR2DS2 interaction awaits thorough assessment.

\section{KIR3DL1 interactions with HLA-Bw4}

KIR3DL1 and KIR3DL2 are proposed to be the evolutionary predecessors of KIR2DL1/2/3 (44). KIR3DL1 recognises HLA class I allotypes that contain the Bw4 motif, a feature of approximately one third of HLA-B allotypes (e.g. HLA-B27, HLA-B57) and 20\% of HLA-A allotypes (e.g. HLAA24) $(45,46)$. To better understand the function of D0 domains and the impact of receptor polymorphism on ligand recognition, we determined the structure of KIR3DL1*001 bound to HLAB*57:01 presenting the self-peptide LSSPVTKSF (LF9) (33) (Figures 2C,D, 3C). Like the KIR2D receptors, KIR3DL1 docked in an orthogonal manner relative to the peptide-binding groove, and created two spatially distinct interfaces. The D0 domain bound to two conserved loops on HLAB*57:01 (residues 16-19 and 88-92) (33). Residues 16-19 of HLA-B*57:01 are conserved across HLA-B allotypes, and most HLA-A allotypes, suggesting that the D0 domain of KIR3DL1 does not confer allotype specificity, but enhances MHC class I binding irrespective of allotype, echoing a concept proposed by Khakoo and colleagues based on functional studies $(33,47)$. Taken together the D0 domain appears to act as an innate sensor of MHC class I proteins.

The second HLA-B*57:01 binding site was generated by the D1 and D2 domains of KIR3DL1 that were positioned over the $\alpha 1$ and $\alpha 2$ helices respectively, akin to the mode of binding observed for KIR2D receptors (Figure 4G,H). In addition to the common contacts made to residues 142-151 of the HLA class I $\alpha 2$ helix, KIR3DL1 also contacted Tyr84 and Arg83 of HLA-B*57:01, the latter a defining residue of the Bw4 motif (33). Further HLA class I contacts included residues 72 and 76, which are also a feature of ligand binding by KIR2DL1 and KIR2DL2 (Table 1) (33). 
One of the primary features of the KIR3DL1/HLA-B*57:01/LF9 interface was the presence of a series of charged interactions that link three loops formed by residues 165-167 from the D1 domain, 199-200 located in the D1/D2 linker region and 278-282 from the D2 domain (Table 1) (33). Pivotal to this network was Glu282 of KIR3DL1, which formed a critical salt-bridge to Lys146 but whose positioning appeared dependent on a series of additional KIR residues including Ser279, Tyr200 and Phe276. Consistent with this, alanine scanning mutagenesis demonstrated that mutation of Glu282 along with Tyr200, Phe276 and Ser279 all impacted binding to HLA-B*57:01 (33).

The D1 domain of KIR2D receptors manifestly dictates HLA binding specificity, with residues at positions 44 and 45 intercalating into the $\alpha 1$ helix. By comparison, the binding interface of the D1 domain of KIR3DL1 was non-ideal, lacking both charge and shape complementarity (33). To probe this further, alanine-scanning mutagenesis was performed on both sides of the interface and revealed somewhat contrasting effects. For example, alanine mutations to KIR residues His278 and Leu166 had little impact on binding to HLA-B*57:01 whereas mutation of the HLA-B*57:01 residues that these residues contact, Arg83 and Ile80, abrogated binding (33). Further analyses of the molecular micro-architecture of the Bw4 motif suggested a salt-bridge between Arg83 and Glu76 that locked the position of the acidic side-chain was critical in allowing KIR3DL1 recognition (48). Notably, in HLA-Bw6 allotypes, this salt bridge is absent as a consequence of the presence of a glycine at position 83, providing an explanation for why KIR3DL receptors do not bind Bw6 allotypes (48).

The Bw4 motif is polymorphic, with a dimorphism at residue 80 (isoleucine or threonine) influencing protection of target cells from NK cell mediated lysis. Early studies by Cella et al. suggested that position 80 modulated the strength of KIR3DL1 interactions since $\mathrm{Bw} 4^{+}$alleles with Ile 80 appeared to be more potent inhibitors of target cell lysis by KIR3DL1 ${ }^{+} \mathrm{NK}$ cells (49). This notion gained further credence as genetic studies linked the presence of certain KIR3DL1 alleles and HLA-Bw4/Ile80 allotypes with delayed progression to AIDS $(49,50)$. In agreement with this, the mutation of Ile80 to 
threonine in HLA-B*57:01 markedly diminished the strength of its interaction with KIR3DL1 (33). Moreover, the ternary complex of KIR3DL1 bound to the HLA-B*57:01.I80T mutant showed that this substitution resulted in the loss of a direct KIR contact that was, in part, replaced by a network of water-mediated interactions (51). However the data pertaining to KIR3DL1 recognition of Bw4 allotypes that encode a threonine is varied. For example, comparison of the recognition of HLA-B27 subtypes by NK clones revealed only HLA-B*27:02 (Ile80) to be susceptible to lysis whereas other HLA-B27 subtypes (Thr80) were resistant (52). Indeed in this study the mutation of Thr80 to isoleucine in HLA-B*27:05 resulted in impaired protection (52). Together these data are indicative of an underlying complexity, likely arising from differences in allotype associated peptide repertoires, together with receptor polymorphism.

\section{KIR3DS1 recognition of HLA ligands}

KIR3DS1 is a variant of KIR3DL1, separated by a unique set of polymorphisms. These include a stop codon that results in the loss of the inhibitory ITIM cytoplasmic motifs and the introduction of a charged amino acid in the transmembrane region that facilitates the interaction with DAP12 to result in switched signalling capacity (53). In addition to these changes, there are discrete polymorphisms in the extracellular domains that impact on the capacity of KIR3DS1 to bind HLA class I molecules. Two of these, S58G and V92M in the D0 domain, are not commonly occurring polymorphisms among KIR3DL1 molecules. Four additional polymorphisms are found in the D1 and D1-D2 loop region of KIR3DS1 (G138W, P163S, L166R and L199P) (Table 2) (54). Together these changes confer a broad lack of HLA-Bw4 reactivity by KIR3DS1; in cellular assays KIR3DS1 is not activated by cells expressing HLA-Bw4 allotypes $(55,56)$ nor does it appear to bind HLA-Bw4 ${ }^{+}$tetramers (57).

The failure of KIR3DS1 to interact with HLA-Bw4 molecules can be attributed to the D1/D2 polymorphisms since the introduction of any single KIR3DS1-like residue into KIR3DL1 
significantly reduced or abolished binding to HLA-A*24:02 (58). The arginine at position 166 in the D1 domain of KIR3DS1 plays a dominant role in limiting binding to $\mathrm{Bw} 4^{+}$allotypes, as the introduction of L166R mutations into KIR3DL1 was found to abrogate binding to a broad panel of HLA tetramers bearing the Bw4 epitope (55). Furthermore, structural modelling based on the KIR3DL1/HLA-B*57:01 structure suggested the introduction of an arginine at 166 would result in both steric and charge clashes with Arg83 of the Bw4 motif itself (55).

Although there is little direct evidence that KIR3DS1 binds HLA-Bw4 molecules there is genetic data suggesting that KIR3DS1, in combination with Bw4/Ile80, plays a role in the control of HIV infection, delaying progression to AIDS (59) as well as protection from opportunistic infections (60). Supporting these observations, Alter has shown that that KIR3DS1 $1^{+} \mathrm{NK}$ cells expand in HIV-infected $\mathrm{Bw}^{+}$donors and in in vitro assays KIR3DS1 $1^{+}$cells can inhibit HIV replication and kill Bw4 $4^{+} \mathrm{HIV}-$ infected cells (61-63). To explain the discrepancy between the binding and functional data, it was proposed that KIR3DS1 may have a very restricted ability to bind to HLA class I, and that the presence of specific peptides when bound to HLA-Bw4, would enhance KIR3DS1 recognition. Indeed, we were able to identify a number of HLA-B*57:01-restricted peptides that permitted weak KIR3DS1 interactions (55). However, it remains unclear what pathogens or immune stress condition would have driven the evolution of such a peptide-restricted system and how highly specific recognition of peptide-MHC complexes by KIR3DS1 would be selected for in populations with highly diverse HLA class I molecules.

\section{Peptide modulates KIR recognition of HLA class I allotypes}

While it is evident that KIRs have specificity for distinct HLA class I allotypes, the HLA class I proteins expressed on any given cell are themselves quite heterogeneous as a result of their association with a diverse repertoire of peptides. Although the peptide forms a critical part of the ligand recognized by the TCR (5), the precise role of peptide and, in particular, how complex peptide 
repertoires collectively act to modulate NK cell recognition of HLA class I molecules is unclear. The culture of TAP-deficient cell lines with individual synthetic peptides to create homogeneous cell surface expressed peptide-HLA class I complexes have demonstrated that: a) peptide was required for NK cell recognition of HLA-B*27:05, HLA-Cw4 and HLA-C*03:04 by their respective KIR (6467) and b) there was significant variation in the capacity of different peptides to facilitate interactions between KIR and HLA class I proteins. Perruzi and colleagues made a systematic series of substitutions in the HLA-B*27:05-binding peptide FRYNGLIHR to show that P7 and P8 were important for recognition. Specifically, substitution of P8 with histidine, alanine and valine at P8 were able to inhibit target cell lysis whereas the presence of a charged residue at this position abrogated protection (64). Furthermore, substitution of a histidine into an otherwise non-permissive peptide could also protect TAP-deficient target cells expressing HLA-B27 from lysis (64). Substitutions at P8 of the HLA-Cw4 binding peptides were similarly able to abrogate KIR2DL1 recognition of target cells (65).

Structural studies have provided insight into understanding why some peptides support KIR interactions whereas others abrogate recognition (Figure 5A-D). The docking of the D1 and D2 domains over the C-terminal region of the peptide is entirely consistent with the functional data implicating P7 and P8 as important for KIR recognition. In the KIR2DL2/HLA-C*03:04 complex, direct contacts were made between the receptor and the GAVDPLLAL peptide loaded onto HLAC*03:04: Leu7 interacted with Leu104 of KIR2DL2 whilst Ala8 bound Gln71 (Figure 5B) (29). Proximal to P8 were KIR2DL2 residues that placed size constraints on the side-chains that would be permissive (29). Accordingly, substitution of a serine at P8 was tolerated, but substitution to larger residues such as tyrosine and lysine abrogated binding of HLA-C*03:04 by KIR2DL2 (29).

KIR2DL1 made more limited contact with the peptide QYDDAVYKL in complex with HLA-Cw4, with Leu9 making a water-mediated contact to Glu187 of KIR2DL1 (Figure 5A) (30). The KIR2DL1 
residues surrounding P8 of the peptide, however, created an electronegative, polar surface that explained the lack of tolerance for acidic amino acids in this position (30,65). Despite having an affinity for HLA-C that was $~ 3.5$ times lower than that of KIR2DL1, KIR2DS1 also shared similar peptide preferences, with P8 substitutions of Tyr7Ala, Lys8Asp and Lys8Glu in the QYDDAVYKL peptide all abrogating KIR2DS1 binding (Figure 5C) (41).

The role of peptide in regulating the interaction of KIR3DL1 with its ligands has been investigated in several contexts. The contribution of peptide to NK cell recognition of HLA class I molecules was realised when mutations within the peptide binding cleft of HLA-B*27:05 (residues 45, 95 and 116) impacted protection from lysis by NK clones (67). Similarly, comparisons of NK cell recognition of HLA-B*51:01 and HLA-B*15:13 also suggested that HLA class I recognition by KIR3LDL1 was sensitive to changes in buried residues that interact with peptide (46). Structural studies of KIR3DL1 bound to the HLA-B*57:01/LF9 complex showed that Leu166 of KIR3DL1 directly contacted the serine at position eight of the peptide (Figure 5D) (33). Substitutions of phenylalanine or histidine at position eight of the LF9 peptide were tolerated by KIR3DL1, with their bulky side chains accommodated by a large solvent-filled cavity surrounding this position $(33,51)$. Further the P8 arginine substitution impaired binding of KIR3DL1 while the presence of a glutamate at this position essentially abrogated KIR3DL1 binding, consistent with earlier work from Peruzzi and colleagues $(33,51,64)$. Somewhat surprisingly the presence of small hydrophobic amino acids substituted at P8 of the LF9 peptide also had a detrimental impact on KIR3DL1 binding. The underlying mechanism remains unclear but presumably reflects disruption of the interface $(33,51)$. Consistent with this, in studies of HLA-B*51:01 the sequence of the HLA class I bound peptide has been suggested to impact upon the conformation of the Bw4 motif as assessed by changes in the reactivity of monoclonal antibodies (68). While the molecular interactions underpinning these changes are unclear, structures of HLA-B27 and HLA-B57 have shown that P8 can interact with a number of residues proximal to the Bw4 motif $(64,69-72)$. It is conceivable that the presence of a charged side-chain at this position 
may disrupt the internal salt-bridge between Glu76 and Arg83 of the Bw4 motif, which in turn could reposition Glu76 and impair KIR3DL1 docking $(48,69)$.

The importance of peptide in KIR/HLA class I interactions has often been assessed in binding assays using HLA class I tetramers that are complexed with viral peptides or variants (51, 73-75). Studies of a naturally occurring HIV peptide variant (TW10) have shown that recognition of HLA-B*57:03 carrying a peptide with a glycine to glutamate mutation at the penultimate residue abrogated KIR3DL1 binding and HLA-B*57:01 binding was similarly lost when an alanine or aspartate was present $(74,75)$. The recognition of HLA-B*57:01 and HLA-A*24:02 by KIR3DL1 also varied with different HIV peptides suggesting that NK cell recognition of HIV-infected cells could potentially be influenced by peptide (74). Additionally studies by Alter identified polymorphisms in a number of HIV proteins that resulted in enhanced binding of KIR-Ig fusion proteins and decreased degranulation of KIR2DL2 ${ }^{+}$NK cells (63). While the data imply that the virus can adapt in order to potentiate inhibitory signalling, the underlying mechanism remains unclear. Both binding and functional studies have shown that there is significant variation in the capacity of peptides to support the interaction between KIR and HLA class I proteins, however the proportion of peptides on the cell surface that can actually mediate KIR interaction is unknown. Indeed, this may be a major factor in the relative potency of some HLA class I allotypes to inhibit NK cell activation. Similarly, whether or not infection or malignant transformation induces changes in peptide repertoire that can impact KIRmediated recognition of HLA class I expressed by target cells requires further investigation. In this context, it is interesting to note that relatively few HLA-B27-binding peptides could confer protection whereas the frequency of peptides that could bind HLA-C*03:04 and confer protection was somewhat higher albeit that the total number of peptides assessed to date is small $(66,67)$. New strategies to both identify and quantify the endogenous peptides bound to different HLA class I allotypes necessary for inhibitory signalling are needed. 


\section{KIR polymorphism: the case of KIR3DLI}

A feature of several of KIR genes is the acquisition of a significant number of polymorphisms. In the case of KIR3DL1, over 110 alleles have presently been described, generating 66 distinct allotypes (76). Early studies using transduced NK cell lines and primary NK cell cultures showed that KIR3DL1 polymorphism modulated the extent of cellular activation after engagement of HLA ligands $(77,78)$. Numerous studies have now shown that such allelic variation influences the frequency of KIR3DL1 expression (79), cell surface expression levels $(80,81)$ and ligand binding $(58,73,77)$. Indeed, KIR3DL1 polymorphism influences the variable recognition of Ile80- versus Thr80-containing Bw4 allotypes and potentially impacts the general hierarchies within HLA-Bw4 molecules bound by KIR3DL1 allotypes (19, 20, 49, 51, 52, 77).

Genetic analyses have subdivided KIR3DL1 sequences into two allelic lineages (*015-like and *005like), which, along with a third encoding the activating KIR3DS1 alleles, are present in all populations studied to date and appear to be maintained via balancing selection (54). Seven amino acid differences distinguish the $* 005$ and $* 015$ canonical sequences, two in the signal sequence, three in the D0 domain and two in the D1/D2 domains (Table 2) (54). Additional polymorphisms are found throughout the whole KIR3DL1 molecule, with a higher number occurring in the extracellular domains, presumably selected under evolutionary pressure (54). These positively selected residues include the HLA contacts, residues 138 and 166 from the D1 domain and residue 199 from the D2 domain $(33,54)$.

Polymorphisms in the D0 domain can influence the strength of binding of KIR3DL1 allotypes to HLA-Bw4 molecules (58). A cluster of polymorphic residues in the D0 domain (position 2, 47 and $54)$ differ between the $* 015$-like and $* 005$-like lineages (Table 2 ). The D0 configuration in $* 005$ promotes stronger binding to the $\mathrm{Bw} 4^{+} \mathrm{HLA}-\mathrm{A} * 24: 02$ and the introduction of a $* 015$-like D0 domain into *005 impaired this interaction (58). The *001 allotype, for which the crystal structure was solved, 
is the result of a recombination event between the $* 015$-like and $* 005$-like lineages and combines the strong D0 domain of $* 005$ with the D1 and D2 domains of *015. This recombinant generates a KIR receptor with very strong ligand interactions (58) and with potent inhibitory capacity (82). Residues 2, 47 and 54 do not contact the HLA directly, nor are they predicted to affect HLA binding (33), yet their variation within this 'innate HLA sensor' domain impacts recognition. There is as yet no clear explanation for these effects but it is tempting to speculate that at least some of these polymorphisms affect clustering or the capacity of the receptor to form higher order complexes.

Position 283 in the D2 domain is another dimorphic residue that differs between the two inhibitory KIR3DL1 families. The presence of Leu283, as found in *005-like allotypes, has been associated with reduced binding to HLA-A*24:02/nef tetramers (58) whilst binding to HLA-Bw4/Thr80 allotypes, including HLA-B*27:05 and HLA-B*44:02, was increased as compared to binding by *015-like molecules that encode a tryptophan at this position (51). Indeed, while Trp283-encoding KIR3DL1 allotypes $(* 015, * 001)$ show a distinct preference for HLA-Bw4/Ile80 allotypes over HLABw4/Thr80 allotypes, *005 binds both HLA subtypes equally well (51). Overall, the *005-lineage appears to have a broader specificity for HLA-Bw4 $4^{+}$molecules $(51,73)$.

In addition to HLA subtype discrimination, the presence of Leu283 has been linked to altered peptide permissiveness for HLA-B*57:01 peptide complexes. KIR3DL1*005 was more tolerant of a P8 leucine substitution and less sensitive to P8 arginine substitution than KIR3DL1*001 (51). While the introduction of a negatively charged aspartate residue into the HLA-B*57:01 restricted HIV gag epitope TW10 (TW10 G9D) decreased binding to *001 and *015 allotypes, *005 was more tolerant of this substitution (51). Recognition of a broader array of peptides by KIR3DL1*005 was also suggested by the work of Thananchai et al, who found that it bound to a greater number of HLAA*24:02 and HLA-B*57:03 peptide complexes than other KIR3DL1 allotypes (73). This modulation in ligand specificity of Leu283 allotypes has been postulated to be a result of a conformation change 
in the D1-D2 interface. Residue 283 falls in the hinge region between the two domains and the substitution of the bulky hydrophobic amino acid tryptophan for leucine may impact the relative juxtapositioning of the D1 and D2 domains $(51,58,73)$.

Polymorphic differences within a lineage can also impact KIR3DL1-HLA class I interactions. In comparing KIR3DL1*002 and *007, both *015-like alleles, Carr et al. identified two polymorphic positions that were responsible for the reduced inhibition of cells expressing the $* 007$ allotype: Arg238Gly in the D2 domain and Ile320Val in the transmembrane domain (78). Position 238 is distal from the ligand binding face of KIR3DL1, which is a common feature of many of the extracellular polymorphisms (33), while the transmembrane polymorphism is unlikely to influence ligand binding. Instead, the variable functional outcomes with different KIR3DL1 allotypes could be the result of a number of factors including the inhibitory signalling capacity, affinity for HLA class I ligand, clustering, cell surface expression levels/stability and peptide sensitivity of the KIR. Delineating these contributions will help clarify the significance of KIR3DL1 polymorphism in genetic association studies linking, allelic variation on the outcome of HIV infection (50), as well as in transplant settings.

\section{D0-D2 KIR: more questions than answers}

Whilst the consecutive (D0)-D1-D2 arrangement of KIR2DL1/2/3 and KIR3DL1/2 molecules results in comparable structural and binding motifs, the D0-D2 configuration of KIR2DL4 and KIR2DL5 has resulted in distinctive structural features. Both KIR2DL4 and KIR2DL5 differ from archetypal KIRs in signalling potential. KIR2DL5 contains both an ITIM and an immunoreceptor tyrosine-based switch motif (ITSM), the functional consequences of which are unclear although the receptor nevertheless retains inhibitory potential $(83,84)$. KIR2DL4 encodes both an ITIM in its cytoplasmic region and an arginine residue in the transmembrane domain that facilitates pairing with the ITAM- 
containing adaptor molecule FcR- $\gamma(85)$. Although KIR2DL4 can transmit inhibitory signals when the transmembrane arginine is mutated $(84,86)$, the predominant functional output of KIR2DL4 is activation as seen by the strong IFN $\gamma$ secretion and limited cytotoxicity in antibody-mediated crosslinking experiments $(87,88)$. Indeed more recently, KIR2DL4 signalling has been proposed to initiate an activation program typical of senescent cells (89).

Understanding ligand recognition and signal transduction by KIR2DL4 is further complicated by its largely endosomal localisation, a property dependent on its ectodomains $(88,90)$. The resolution of the structure of KIR2DL4 showed that like other KIR2D receptors, the D0-D2 domains of KIR2DL4 adopted a "V" architecture, yet with a less acute hinge angle of $\sim 85^{\circ}$ relative to that between the D1 and D2 domains in other KIR (34). Most notably, however, unlike other KIR receptors, which exist as monomers in solution, KIR2DL4 was observed as a tetramer (Figure 2) where the concentrationdependent oligomerisation was driven by the self-association of the D0 domains (34). The oligomerisation interface utilised residues that previously featured in the interaction between KIR3DL1 and HLA-B*57:01(33, 34). Structural comparison between KIR2DL4 and KIR3DL1 demonstrate that while the D2 domains overlay very closely, the D0 domains deviate significantly. Furthermore, KIR2DL4 has an unusual disulfide pairing between Cys10 and Cys28, whereas Cys28 is paired to Cys74 in all other KIR D0 domains. In the context of KIR2DL4, the D0 domain appears to function as a 'self-association module' rather than an 'innate HLA sensor' as for KIR3DL1.

Whether ligand binding by KIR2DL4 and KIR2DL5 utilises analogous residues to KIR2DL1/2/3 and KIR3DL1 is presently unknown. KIR2DL4 does not appear to bind classical HLA class I molecules with a recent study reporting no binding of recombinant KIR2DL4 to a panel of 100 HLA class I allotypes (34). Association between KIR2DL4 and the non-classical MHC molecule HLA-G, however, have been reported with a KIR2DL4-Ig fusion protein binding to HLA-G expressing cell lines (91-93). Similarly soluble HLA-G has been shown to stimulate cytokine production from resting 
NK cells (88). However a number of additional studies have failed to observe an interaction between KIR2DL4 and HLA-G either via direct binding or functional approaches (34, 94-96). Alternatively, heparanated proteoglycans have been proposed as KIR2DL4 ligands, found to interact with the D0 domain and affect endosomal uptake of KIR2DL4 independently of HLA-G (97). Solution phase studies demonstrating unambiguous interactions between purified KIR2DL4 and KIR2DL5 with their ligands are important for refining our understanding of the functions of KIR2DL4 and KIR2DL5 and ultimately their physiological roles. Given the impact of oligomerisation on membrane trafficking, structural insights into the organisation of KIR2DL4 into higher order oligomers may open new avenues of investigation into these distinctive KIR.

\section{CD94-NKG2 recognition of $H L A-E$}

An alternative mechanism for NK cell recognition of HLA class I molecules is mediated through the heterodimeric CD94-NKG2 receptors that bind the non-classical HLA class I molecule, HLA-E (98, 99). Unlike the polymorphic classical HLA class I molecules, HLA-E is essentially dimorphic, with two alleles varying only at position 107 each being present in most populations at frequencies of approximately 0.5 (100) (101). HLA-E is the most evolutionary conserved of the HLA class I molecules with the murine Qa- $1^{\text {b }}$ molecule now considered to be a direct ortholog $(102,103)$. Transfection of 721.221 cells that express HLA-E but not endogenous HLA-A, -B or -C with plasmids encoding some (but not all) HLA class I alleles protected the transfected cells from lysis by NK cells expressing CD94-NKG2A $(104,105)$. This protective effect was dependent on residues 311 of the HLA class I allotype $(98,99)$. HLA-E has a preference for binding peptides with a methionine at P2 and leucine at P9 (106), features that are largely conserved across the leader sequences of HLA class I proteins, the notable exceptions being a group of HLA-B allotypes that possess a threonine at P2 and HLA-E itself (98). Moreover studies from Braud and colleagues revealed the loading of peptides into HLA-E was largely TAP-dependent (107). Thus the interaction of HLA-E bound to HLA class I-derived leader sequence peptides with CD94-NKG2A represents a 
means by which NK cells can indirectly monitor the "global" expression of classical HLA class I proteins together with the integrity of the antigen processing machinery.

The CD94-NKG2 receptors consist of an invariant CD94 polypeptide disulfide-bonded to a member of the NKG2 family, most typically NKG2A or NKG2C (108-110). Like many immunoreceptor families, there are both inhibitory and activating forms of the NKG2 subunit $(111,112) . N K G 2 A$ is the only gene encoding an inhibitory receptor and directs expression of both NKG2A and its alternatively spliced variant NKG2B $(112,113)$. While there are a number of genes encoding activating NKG2 subunits, as a group they have a limited capacity to assemble with CD94. Notably NKG2D does not associate with CD94 but forms a homodimeric receptor that recognises stressinduced ligands $(109,114,115)$. Of the remaining activating isoforms, CD94-NKG2C heterodimers are expressed at the cell surface, but little evidence exists to suggest that NKG2E and -F form functional heterodimers with CD94 at the cell surface, although $\mathrm{NKG} 2 \mathrm{H}$, an alternatively spliced variant of $\mathrm{NKG} 2 \mathrm{E}$, has been identified on a $\mathrm{T}$ cell clone (116-118). In contrast to NKG2A, the NKG2C subunit lacks an ITIM but like activating KIR is associated with adaptor protein DAP12 and can trigger cellular activation (119).

The ternary CD94-NKG2A/HLA-E structure yielded valuable insight into the mode of ligand recognition, with little conformational change evident in either HLA-E or CD94-NKG2A when compared to their binary structures (Figure 6) (120, 121). Somewhat surprisingly, the CD94 subunit dominated the contacts with HLA-E, indicating that the primary function of the CD94 subunit was ligand binding (120-122). However, as CD94 lacks the capacity to signal, the NKG2A subunit dictated signalling following recognition of HLA-E.

CD94-NKG2A bound HLA-E in a diagonal orientation positioned toward the C-terminal end of the peptide-binding cleft (121) (Figure 6A-C). In contrast to the KIR/HLA complexes, CD94-NKG2A 
interacted with a greater area of the bound peptide (121). The structures of HLA-E bound to leader peptides from HLA-B7 (VMAPTRVLL) (123, 124), HLA-G (VMAPTRLFL) (125), HLA-Cw7 (VMAPRALLL)(125), HLA-C*03:04 (VMAPRTLIL) (126) and HLA-B27 (VTAPRTLLL) (124) showed that each peptide sits in an analogous manner within the cleft, with a more extensive set of contacts distributed along the length of the peptide bound to HLA-E than is typical for classical MHC class I (123). The relatively strict requirements for peptide to bind HLA-E significantly constrain the number of peptides capable of supporting its interaction with CD94-NKG2 receptors.

Surface plasmon resonance analyses demonstrated the interaction between CD94-NKG2A and peptide-laden HLA-E to be typically $0.5-20 \mu \mathrm{M}$, similar to that reported between inhibitory KIR2DL1 and KIR2DL2/3 with C2 and C1 allotypes respectively $(29,120,127-129)$. Indeed, the sequence of these HLA-E bound peptides was critical for the interaction with CD94-NKG2A, as the receptor made contacts with P5, P7 and P8 (Figure 6D). The P5-Arg sat in a cleft formed between CD94 and NKG2A (121); P8-Phe was positioned in a pocket formed by CD94, consistent with binding studies showing that P8 could modulate the affinity of the interaction (120, 127, 128); Gln112 of CD94 played a key role in determining the peptide specificity of the receptor, intercalating between the P5 arginine and the P8 phenylalanine and making main chain contacts with threonine at P6. Together these interactions explain why hydrophobic residues such as leucine, valine and isoleucine, all of which are present in distinct HLA class I allotypes, were tolerated at P8 and why substitutions of arginine at P5 abrogated receptor binding (106). More broadly, the complex illustrated the central role the peptide plays in interactions with both HLA-E and the NK receptor, providing in essence a dual layer of specificity.

While the structure of CD94-NKG2C is not yet determined, the ectodomain of NKG2C receptor shares high levels sequence similarity with NKG2A (112). Despite this, the CD94-NKG2C heterodimer had a six to eight-fold decrease in affinity for HLA-E compared to CD94-NKG2A, 
regardless of the peptide bound to HLA-E $(120,128)$. Indeed similar differences between CD94NKG2A and -NKG2C binding were also evident when HLA-E was bound to peptides derived from variants of the cytomegalovirus (CMV) UL40 protein, which mimic HLA leader sequences (130, 131). While this could reflect direct but differing contributions of the NKG2 subunits to the interaction, structural analyses and mutagenesis studies also suggest that the reduced affinity of CD94-NKG2C for HLA-E may stem from NKG2 differences at the heterodimer interface that have the potential to impact the conformation of CD94 $(120,121)$.

There is now a wealth of data linking elevated CD94-NKG2C expression with CMV infections,(132134). For example in vitro studies showed that culture of NK cells with CMV-infected fibroblasts induced an expansion of $\mathrm{NKG}_{2} \mathrm{C}^{+}$cells (132-134). The mechanism responsible appears to involve ligand recognition since silencing of HLA-E expression in infected fibroblasts impairs the induction of NKG2C (135). The high degree of sequence identity shared between the ectodomains of NKG2A and NKG2C, combined with structural and binding data that show both a dominant role for CD94 and the extensive peptide constraints required to permit HLA-E binding to CD94-NKG2A, suggest that very few peptides will have the capacity to engage the activating receptor $(112,121)$. Rather, signalling via CD94-NKG2C may depend on the overall cell surface level of HLA-E which in the context of infection may be upregulated due to pro-inflammatory cytokines such as IFN $\gamma$. Further molecular definition of how CD94-NKG2C interacts with its ligands is required to better understand the significance of the expansion of $\mathrm{NKG}_{2} \mathrm{C}^{+}$cells following CMV infection and its relationship with their elevated functional capacity $(136,137)$.

\section{Conclusions \& Future Directions}

Structural studies have provided major insights into the molecular interactions underpinning NK cell recognition of HLA class I proteins and the critical determinants of receptor specificity. Indeed this approach has revealed that recognition is largely focused on elements conserved across large groups 
of HLA class I allotypes. This strategy is a feature of the interaction of both KIR and CD94-NKG2 receptors with their respective ligands, in the case of KIR utilising a conserved platform on the $\alpha 2$ helix of classical HLA class I proteins while CD94-NKG2 receptors engagement is dependent on conserved peptides from HLA class I-derived signal sequences.

Unlike T cells, individual NK cells frequently express multiple MHC class I reactive receptors, and, in the case of KIR, bind multiple HLA class I allotypes that typically associate with thousands of different peptides within any given cell. This in essence generates a highly complex recognition matrix, dependent not only on the expression of multiple distinct receptors on the NK cell but also on the number and type of ligands expressed by the target cell. It is unclear if the inhibitory receptors all act in a cumulative manner, being recruited to the same immune synapses with "additive" signalling, or whether differences in ligand affinity, membrane mobility and/or capacity to cluster results in the formation of distinct "microclusters" with their respective HLA class I ligands.

Critical to unravelling NK cell receptor interactions with HLA class I ligands is an understanding of the contributions of the HLA-bound peptide. The KIR/HLA system necessarily requires a degree of tolerance for different peptides in the receptor/ligand interface since KIR are specific for multiple HLA class I allotypes which typically have additional polymorphisms in the peptide-binding groove that may impact on the peptide repertoire. In contrast to KIR ligands, the minimal allelic variation within HLA-E has allowed for the evolution of a recognition mechanism that is exquisitely peptide specific. Somewhat paradoxically, the strict peptide features that allow both binding to HLA-E and interaction with CD94-NKG2 receptors has provided a defined molecular target that can be exploited by pathogens via molecular mimicry.

A number of distinct peptide-HLA class I complexes, either in the form of tetramers or as cell surface complexes expressed on TAP-deficient target cells, have been shown to bind KIR or inhibit NK cell 
activation $(64,67,73,74)$, yet it remains unclear whether these peptides have sufficient potency to transduce inhibitory signals in an in vivo context. Are the peptides that actually drive inhibitory signalling a much smaller subset of those found to interact in tetramer binding studies? Alternatively, inhibitory signalling may stem from cumulative interactions with a large number of different peptides bound to a given HLA class I allotype. Such questions are important for at least two reasons. Firstly, the capacity of different HLA class I allotypes to bind peptides that promote high affinity interactions may drive their relative inhibitory potency. HLA class I allotypes in which $10 \%$ of peptides support high affinity interactions with KIR may effectively appear to be better KIR ligands than those where only $1 \%$ allow for such interactions. Secondly, if the proportion of peptides that actually promote in vivo interactions is small, then there is an increased potential for infection-induced changes to the peptide repertoire modulating KIR-mediated recognition of HLA class I.

While interactions between individual KIR and HLA class I allotypes have been assessed extensively, in vitro studies are suggestive of significant differences between allotypes that all belong within defined KIR ligand groups. For example, HLA-Cw7 has been suggested to be a "strong" ligand for KIR2DL2/3 compared to other C1 ligands (138). Given the apparent conservation of contact residues across all $\mathrm{C} 1$ ligands, understanding of the features, beyond simply the presence of an Asn80, that modulate the strength of these interactions may be important. Furthermore these more subtle but potentially significant differences may extend beyond classical KIR/ligand pairs. For example, while KIR2DL2 preferentially interacts with $\mathrm{C} 1$ allotypes, it nevertheless has the capacity to recognise at least some $\mathrm{C} 2$ allotypes. In $\mathrm{C} 1 / \mathrm{C} 2$ heterozygous individuals, the extent to which KIR2DL2 recognises $\mathrm{C} 2$ allotypes, and indeed whether only a subset of $\mathrm{C} 2$ allotypes can interact and/or augment signalling, remains ill-defined. Understanding the extent to which allelic variation in HLA class I molecules impacts KIR recognition is critical to understanding the increasing number of genetic association studies linking the presence of particular KIR and HLA class I genes with disease outcomes. 


\section{Figure Legends:}

Figure 1: Members of the KIR family and their HLA class I ligands. Members of the KIR family are divided into activating and inhibitory receptors based upon the length of their cytoplasmic tail (long, L, or short, S). Long-tailed inhibitory receptors encode one or two immunoreceptor tyrosine-based inhibitory motifs (ITIM) within their cytoplasmic tail, with KIR3DL2 and KIR2DL5 containing immunoreceptor tyrosine-based switch motif (ITSM)-like motifs. Short-tailed activating receptors contain a charged amino acid within their transmembrane region, which facilitates association with immunoreceptor tyrosine-based activation motif (ITAM)-containing adaptor proteins such as DAP12 or FcR $\gamma$. The extracellular region of KIR is composed of two or three immunoglobulin-like domains designated D0, D1 or D2. These domains form a V-shaped structure that interact with their HLA class I ligand on the target cell. Although the ligands for the inhibitory KIR have been well characterised, uncertainty still exists around some activating KIR ligands.

Figure 2: Interaction of KIR2DL and KIR3DL with HLA class I ligands and the structure of KIR2DL4. The general docking mode of KIR2DL and KIR3DL receptors on HLA class I ligands is depicted. Two orthogonal views are shown of KIR2DL1 in complex with HLA-C*04:01 (A and B) (30) and KIR3DL1 in complex with HLA-B*57:01 (C and D) (33). The monomeric structure of KIR2DL4 is shown (E) and the KIR2DL4 tetramer as observed in the crystal lattice (F). The D0, D1 and D2 domains are noted. (F) The major hinge angles for all KIR-HLA complex structures solved to date (29-31, 33). (G) The angular difference in docking position of the D1 and D2 (orthogonal to the hinge-angle) for all the complexes solved to date $(29-31,33)$. The range in angular difference is shown. 
Figure 3: Conservation of the KIR binding footprint to their respective HLA. Footprint of KIR2DL2 (A), KIR2DS2 (B) and KIR3DL1 (C) overlaid on that of KIR2DL1. For panels A-C conserved contacts are coloured gold, unique contacts are coloured by KIR; KIR2DL1 in dark blue, KIR2DL2 in purple, KIR2DS2 in brown and KIR3DL1 in teal. (D) Conserved KIR binding footprint on HLA. Residues contacted across all KIR-HLA complexes are coloured light blue. Of these, the contacts that have a conserved interaction with a specific KIR residue are coloured gold.

Figure 4: Interaction between KIR and their respective HLA ligands. Interactions between the KIR and HLA are coloured by loop for (A, B) KIR2DL2-HLA-C*03:04, (C, D) KIR2DL1-HLA-C*04:01, (E, F) KIR2DS2-HLA-A*11:01 and (G, H) KIR3DL1-HLA-B*57:01. Left-hand panels depict D1 loops A'-B loop is coloured pink, the C-C' loop is cyan and the E-F loop is orange. Right-hand panels depict the D2 loops and D1-D2 linker: the D1-D2 linker is coloured green, the B-C loop is coloured yellow and the F-F' hinge loop is coloured wheat.

Figure 5: Involvement of the peptides at the KIR-HLA interface. KIR residues that are involved in direct or water mediated peptide contacts are depicted for (A) KIR2DL1-HLA-C*04:01, (B) KIR2DL2-HLA-C*03:04, (C) KIR2DS2-HLA-A*11:01 and (D) KIR3DL1-HLA-B*57:01. Hydrogen bonds/salt bridges are shown in blue, VDW contacts are shown in red. Panel C shows that there is no peptide contact by the KIR in the KIR2DS2/HLA-A*11:01 complex.

Figure 6: The structure of CD94-NKG2A in complex with HLA. (A and B) Orthogonal views of NKG2A-CD94 in complex with HLA-E (121). (C) The binding footprint of CD94-NKG2A on HLAE. The contacts from CD94 are coloured light brown, those to NKG2A are coloured dark brown. Contacts to both CD94 and NKG2A are coloured red. (D) Peptide contacts to NKG2A (dark brown) 
and CD94 (light brown). Of note, the Gln112 on CD94 interposes the peptide, binding between Arg5 and Phe7. 


\section{References}

1. Long EO, Sik Kim H, Liu D, Peterson ME, Rajagopalan S. Controlling Natural Killer Cell Responses: Integration of Signals for Activation and Inhibition. Annual Review of Immunology.2013;31:227-258.

2. Older Aguilar AM, Guethlein LA, Adams EJ, Abi-Rached L, Moesta AK, Parham P. Coevolution of killer cell Ig-like receptors with HLA-C to become the major variable regulators of human NK cells. J Immunol.2010;185:4238-4251.

3. Parham P, et al. Nature of polymorphism in HLA-A, -B, and -C molecules. Proc Natl Acad Sci U S A.1988;85:4005-4009.

4. Zemmour J, Parham P. Distinctive polymorphism at the HLA-C locus: implications for the expression of HLA-C. J Exp Med.1992;176:937-950.

5. Rossjohn J, Gras S, Miles JJ, Turner SJ, Godfrey DI, McCluskey J. T Cell Antigen Receptor Recognition of Antigen-Presenting Molecules. Annu Rev Immunol.2014.

6. Willcox BE, Thomas LM, Bjorkman PJ. Crystal structure of HLA-A2 bound to LIR-1, a host and viral major histocompatibility complex receptor. Nat Immunol.2003;4:913-919.

7. Berry R, Rossjohn J, Brooks AG. The Ly49 natural killer cell receptors: a versatile tool for viral self-discrimination. Immunol Cell Biol.2014;92:214-220.

8. Colonna M, Samaridis J. Cloning of immunoglobulin-superfamily members associated with HLA-C and HLA-B recognition by human natural killer cells. Science.1995;268:405-408.

9. Wagtmann N, et al. Molecular clones of the p58 NK cell receptor reveal immunoglobulinrelated molecules with diversity in both the extra- and intracellular domains. Immunity.1995;2:439449.

10. Lanier LL, Corliss BC, Wu J, Leong C, Phillips JH. Immunoreceptor DAP12 bearing a tyrosine-based activation motif is involved in activating NK cells. Nature.1998;391:703-707. 
11. Burshtyn DN, et al. Recruitment of tyrosine phosphatase HCP by the killer cell inhibitor receptor. Immunity.1996;4:77-85.

12. Mason LH, Willette-Brown J, Taylor LS, McVicar DW. Regulation of Ly49D/DAP12 signal transduction by Src-family kinases and CD45. J Immunol.2006;176:6615-6623.

13. Yawata M, Yawata N, Abi-Rached L, Parham P. Variation within the human killer cell immunoglobulin-like receptor (KIR) gene family. Crit Rev Immunol.2002;22:463-482.

14. Anderson SK, Ortaldo JR, McVicar DW. The ever-expanding Ly49 gene family: repertoire and signaling. Immunol Rev.2001;181:79-89.

15. Colonna M, Brooks EG, Falco M, Ferrara GB, Strominger JL. Generation of allospecific natural killer cells by stimulation across a polymorphism of HLA-C. Science.1993;260:1121-1124. 16. Biassoni R, et al. Amino acid substitutions can influence the natural killer (NK)-mediated recognition of HLA-C molecules. Role of serine-77 and lysine-80 in the target cell protection from lysis mediated by "group 2" or "group 1" NK clones. J Exp Med.1995;182:605-609.

17. Moretta A, et al. Identification of four subsets of human CD3-CD16+ natural killer (NK) cells by the expression of clonally distributed functional surface molecules: correlation between subset assignment of NK clones and ability to mediate specific alloantigen recognition. J Exp Med.1990;172:1589-1598.

18. Moretta A, et al. P58 molecules as putative receptors for major histocompatibility complex (MHC) class I molecules in human natural killer (NK) cells. Anti-p58 antibodies reconstitute lysis of MHC class I-protected cells in NK clones displaying different specificities. J Exp Med.1993;178:597-604.

19. Litwin V, Gumperz J, Parham P, Phillips JH, Lanier LL. NKB1: a natural killer cell receptor involved in the recognition of polymorphic HLA-B molecules. J Exp Med.1994;180:537-543.

20. Gumperz JE, Litwin V, Phillips JH, Lanier LL, Parham P. The Bw4 public epitope of HLAB molecules confers reactivity with natural killer cell clones that express NKB1, a putative HLA receptor. J Exp Med.1995;181:1133-1144. 
21. Pende D, et al. The natural killer cell receptor specific for HLA-A allotypes: a novel member of the p58/p70 family of inhibitory receptors that is characterized by three immunoglobulin-like domains and is expressed as a $140-\mathrm{kD}$ disulphide-linked dimer. J Exp Med.1996;184:505-518.

22. Dohring C, Scheidegger D, Samaridis J, Cella M, Colonna M. A human killer inhibitory receptor specific for HLA-A1,2. J Immunol.1996;156:3098-3101.

23. Trowsdale J, Barten R, Haude A, Stewart CA, Beck S, Wilson MJ. The genomic context of natural killer receptor extended gene families. Immunol Rev.2001;181:20-38.

24. Wilson MJ, et al. Plasticity in the organization and sequences of human KIR/ILT gene families. Proc Natl Acad Sci U S A.2000;97:4778-4783.

25. Middleton D, Gonzelez F. The extensive polymorphism of KIR genes. Immunology.2010;129:8-19.

26. Marsh SG, et al. Killer-cell immunoglobulin-like receptor (KIR) nomenclature report, 2002. Hum Immunol.2003;64:648-654.

27. Moretta A, et al. Existence of both inhibitory (p58) and activatory (p50) receptors for HLAC molecules in human natural killer cells. J Exp Med.1995;182:875-884.

28. Moretta L. Introduction: NK cells: origin, receptors and specificity. Semin Immunol.1995;7:57-59.

29. Boyington JC, Motyka SA, Schuck P, Brooks AG, Sun PD. Crystal structure of an NK cell immunoglobulin-like receptor in complex with its class I MHC ligand. Nature.2000;405:537-543. 30. Fan QR, Long EO, Wiley DC. Crystal structure of the human natural killer cell inhibitory receptor KIR2DL1-HLA-Cw4 complex. Nat Immunol.2001;2:452-460.

31. Liu J, Xiao Z, Ko HL, Shen M, Ren EC. Activating killer cell immunoglobulin-like receptor 2DS2 binds to HLA-A*11. Proc Natl Acad Sci U S A.2014;111:2662-2667.

32. Snyder GA, Brooks AG, Sun PD. Crystal structure of the HLA-Cw3 allotype-specific killer cell inhibitory receptor KIR2DL2. Proc Natl Acad Sci U S A.1999;96:3864-3869. 
33. Vivian JP, et al. Killer cell immunoglobulin-like receptor 3DL1-mediated recognition of human leukocyte antigen B. Nature.2011;479:401-405.

34. Moradi S, et al. The structure of the atypical Killer Cell Immunoglobulin-like Receptor, KIR2DL4. J Biol Chem.2015.

35. Graef T, et al. KIR2DS4 is a product of gene conversion with KIR3DL2 that introduced specificity for HLA-A*11 while diminishing avidity for HLA-C. J Exp Med.2009;206:2557-2572. 36. Maenaka K, Juji T, Stuart DI, Jones EY. Crystal structure of the human p58 killer cell inhibitory receptor (KIR2DL3) specific for HLA-Cw3-related MHC class I. Structure.1999;7:391398.

37. Saulquin X, Gastinel LN, Vivier E. Crystal structure of the human natural killer cell activating receptor KIR2DS2 (CD158j). J Exp Med.2003;197:933-938.

38. Winter CC, Long EO. A single amino acid in the p58 killer cell inhibitory receptor controls the ability of natural killer cells to discriminate between the two groups of HLA-C allotypes. J Immunol.1997;158:4026-4028.

39. Moesta AK, Norman PJ, Yawata M, Yawata N, Gleimer M, Parham P. Synergistic polymorphism at two positions distal to the ligand-binding site makes KIR2DL2 a stronger receptor for HLA-C than KIR2DL3. J Immunol.2008;180:3969-3979.

40. Pende D, et al. Anti-leukemia activity of alloreactive NK cells in KIR ligand-mismatched haploidentical HSCT for pediatric patients: evaluation of the functional role of activating KIR and redefinition of inhibitory KIR specificity. Blood.2009;113:3119-3129.

41. Stewart CA, et al. Recognition of peptide-MHC class I complexes by activating killer immunoglobulin-like receptors. Proc Natl Acad Sci U S A.2005;102:13224-13229.

42. Vales-Gomez M, Reyburn HT, Erskine RA, Strominger J. Differential binding to HLA-C of p50-activating and p58-inhibitory natural killer cell receptors. Proc Natl Acad Sci U S

A.1998;95:14326-14331. 
43. Winter CC, Gumperz JE, Parham P, Long EO, Wagtmann N. Direct binding and functional transfer of NK cell inhibitory receptors reveal novel patterns of HLA-C allotype recognition. J Immunol.1998;161:571-577.

44. Rajalingam R, Parham P, Abi-Rached L. Domain shuffling has been the main mechanism forming new hominoid killer cell Ig-like receptors. J Immunol.2004;172:356-369.

45. Gumperz JE, et al. Conserved and variable residues within the Bw4 motif of HLA-B make separable contributions to recognition by the NKB1 killer cell-inhibitory receptor. J Immunol.1997;158:5237-5241.

46. Sanjanwala B, Draghi M, Norman PJ, Guethlein LA, Parham P. Polymorphic sites away from the Bw4 epitope that affect interaction of Bw4+ HLA-B with KIR3DL1. J Immunol.2008;181:6293-6300.

47. Khakoo SI, Geller R, Shin S, Jenkins JA, Parham P. The D0 domain of KIR3D acts as a major histocompatibility complex class I binding enhancer. J Exp Med.2002;196:911-921. 48. Saunders PM, et al. The Interaction of KIR3DL1*001 with HLA Class I Molecules Is Dependent upon Molecular Microarchitecture within the Bw4 Epitope. J Immunol.2015;194:781789.

49. Cella M, Longo A, Ferrara GB, Strominger JL, Colonna M. NK3-specific natural killer cells are selectively inhibited by Bw4-positive HLA alleles with isoleucine 80. J Exp Med.1994;180:1235-1242.

50. Martin MP, et al. Innate partnership of HLA-B and KIR3DL1 subtypes against HIV-1. Nat Genet.2007;39:733-740.

51. O'Connor GM, et al. Mutational and Structural Analysis of KIR3DL1 Reveals a LineageDefining Allotypic Dimorphism That Impacts Both HLA and Peptide Sensitivity. J Immunol.2014;192:2875-2884.

52. Luque I, et al. Threonine 80 on HLA-B27 confers protection against lysis by a group of natural killer clones. Eur J Immunol.1996;26:1974-1977. 
53. Abi-Rached L, Parham P. Natural selection drives recurrent formation of activating killer cell immunoglobulin-like receptor and Ly49 from inhibitory homologues. J Exp Med.2005;201:1319-1332.

54. Norman PJ, et al. Unusual selection on the KIR3DL1/S1 natural killer cell receptor in Africans. Nat Genet.2007;39:1092-1099.

55. O'Connor GM, et al. Peptide-dependent recognition of HLA-B*57:01 by KIR3DS1. J Virol.2015.

56. Carr WH, Rosen DB, Arase H, Nixon DF, Michaelsson J, Lanier LL. Cutting Edge: KIR3DS1, a gene implicated in resistance to progression to AIDS, encodes a DAP12-associated receptor expressed on NK cells that triggers NK cell activation. J Immunol.2007;178:647-651.

57. Gillespie GM, Bashirova A, Dong T, McVicar DW, Rowland-Jones SL, Carrington M. Lack of KIR3DS1 binding to MHC class I Bw4 tetramers in complex with CD8+ T cell epitopes. AIDS Res Hum Retroviruses.2007;23:451-455.

58. Sharma D, et al. Dimorphic motifs in D0 and D1+D2 domains of killer cell Ig-like receptor 3DL1 combine to form receptors with high, moderate, and no avidity for the complex of a peptide derived from HIV and HLA-A*2402. J Immunol.2009;183:4569-4582.

59. Martin MP, et al. Epistatic interaction between KIR3DS1 and HLA-B delays the progression to AIDS. Nat Genet.2002;31:429-434.

60. Qi Y, et al. KIR/HLA pleiotropism: protection against both HIV and opportunistic infections. PLoS Pathog.2006;2:e79.

61. Alter G, et al. Differential natural killer cell-mediated inhibition of HIV-1 replication based on distinct KIR/HLA subtypes. J Exp Med.2007;204:3027-3036.

62. Alter G, et al. HLA class I subtype-dependent expansion of KIR3DS1+ and KIR3DL1+ NK cells during acute human immunodeficiency virus type 1 infection. J Virol.2009;83:6798-6805.

63. Alter G, et al. HIV-1 adaptation to NK-cell-mediated immune pressure.

Nature.2011;476:96-100. 
64. Peruzzi M, Parker KC, Long EO, Malnati MS. Peptide sequence requirements for the recognition of HLA-B*2705 by specific natural killer cells. J Immunol.1996;157:3350-3356.

65. Rajagopalan S, Long EO. The direct binding of a p58 killer cell inhibitory receptor to human histocompatibility leukocyte antigen (HLA)-Cw4 exhibits peptide selectivity. J Exp Med.1997;185:1523-1528.

66. Zappacosta F, Borrego F, Brooks AG, Parker KC, Coligan JE. Peptides isolated from HLA$\mathrm{CW}^{*} 0304$ confer different degrees of protection from natural killer cell-mediated lysis. Proc Natl Acad Sci U S A.1997;94:6313-6318.

67. Malnati MS, et al. Peptide specificity in the recognition of MHC class I by natural killer cell clones. Science.1995;267:1016-1018.

68. Takamiya Y, Sakaguchi T, Miwa K, Takiguchi M. Role of HLA-B*5101 binding nonamer peptides in formation of the HLA-Bw4 public epitope. Int Immunol.1996;8:1027-1034.

69. Stewart-Jones GB, di Gleria K, Kollnberger S, McMichael AJ, Jones EY, Bowness P. Crystal structures and KIR3DL1 recognition of three immunodominant viral peptides complexed to HLA-B*2705. Eur J Immunol.2005;35:341-351.

70. Stewart-Jones GB, et al. Structures of three HIV-1 HLA-B*5703-peptide complexes and identification of related HLAs potentially associated with long-term nonprogression. J Immunol.2005;175:2459-2468.

71. Hulsmeyer M, et al. Thermodynamic and structural equivalence of two HLA-B27 subtypes complexed with a self-peptide. J Mol Biol.2005;346:1367-1379.

72. Madden DR, Gorga JC, Strominger JL, Wiley DC. The three-dimensional structure of HLAB27 at 2.1 A resolution suggests a general mechanism for tight peptide binding to MHC. Cell.1992;70:1035-1048.

73. Thananchai H, et al. Cutting Edge: Allele-specific and peptide-dependent interactions between KIR3DL1 and HLA-A and HLA-B. J Immunol.2007;178:33-37. 
74. Fadda L, et al. Common HIV-1 peptide variants mediate differential binding of KIR3DL1 to HLA-Bw4 molecules. J Virol.2011;85:5970-5974.

75. Brackenridge $\mathrm{S}$, et al. An early HIV mutation within an HLA-B*57-restricted T cell epitope abrogates binding to the killer inhibitory receptor 3DL1. J Virol.2011;85:5415-5422.

76. Robinson J, Halliwell JA, McWilliam H, Lopez R, Marsh SG. IPD--the Immuno Polymorphism Database. Nucleic Acids Res.2013;41:D1234-1240.

77. O'Connor GM, Guinan KJ, Cunningham RT, Middleton D, Parham P, Gardiner CM. Functional polymorphism of the KIR3DL1/S1 receptor on human NK cells. J Immunol.2007;178:235-241.

78. Carr WH, Pando MJ, Parham P. KIR3DL1 polymorphisms that affect NK cell inhibition by HLA-Bw4 ligand. J Immunol.2005;175:5222-5229.

79. Li H, Pascal V, Martin MP, Carrington M, Anderson SK. Genetic control of variegated KIR gene expression: polymorphisms of the bi-directional KIR3DL1 promoter are associated with distinct frequencies of gene expression. PLoS Genet.2008;4:e1000254.

80. Gardiner CM, et al. Different NK cell surface phenotypes defined by the DX9 antibody are due to KIR3DL1 gene polymorphism. J Immunol.2001;166:2992-3001.

81. Pando MJ, Gardiner CM, Gleimer M, McQueen KL, Parham P. The protein made from a common allele of KIR3DL1 (3DL1*004) is poorly expressed at cell surfaces due to substitution at positions 86 in Ig domain 0 and 182 in Ig domain 1. J Immunol.2003;171:6640-6649.

82. Yawata M, Yawata N, Draghi M, Little AM, Partheniou F, Parham P. Roles for HLA and KIR polymorphisms in natural killer cell repertoire selection and modulation of effector function. $\mathbf{J}$ Exp Med.2006;203:633-645.

83. Estefania E, Flores R, Gomez-Lozano N, Aguilar H, Lopez-Botet M, Vilches C. Human KIR2DL5 is an inhibitory receptor expressed on the surface of NK and T lymphocyte subsets. J Immunol.2007;178:4402-4410. 
84. Yusa S, Catina TL, Campbell KS. SHP-1- and phosphotyrosine-independent inhibitory signaling by a killer cell Ig-like receptor cytoplasmic domain in human NK cells. $\mathbf{J}$ Immunol.2002;168:5047-5057.

85. Kikuchi-Maki A, Catina TL, Campbell KS. Cutting edge: KIR2DL4 transduces signals into human NK cells through association with the Fc receptor gamma protein. $\mathbf{J}$ Immunol.2005;174:3859-3863.

86. Faure M, Long EO. KIR2DL4 (CD158d), an NK cell-activating receptor with inhibitory potential. J Immunol.2002;168:6208-6214.

87. Rajagopalan S, Fu J, Long EO. Cutting edge: induction of IFN-gamma production but not cytotoxicity by the killer cell Ig-like receptor KIR2DL4 (CD158d) in resting NK cells. J Immunol.2001;167:1877-1881.

88. Rajagopalan S, et al. Activation of NK cells by an endocytosed receptor for soluble HLA-G. PLoS Biol.2006;4:e9.

89. Rajagopalan S, Long EO. Cellular senescence induced by CD158d reprograms natural killer cells to promote vascular remodeling. Proc Natl Acad Sci U S A.2012;109:20596-20601. 90. Rajagopalan S, Moyle MW, Joosten I, Long EO. DNA-PKcs controls an endosomal signaling pathway for a proinflammatory response by natural killer cells. Sci Signal.2010;3:ra14. 91. Ponte M, et al. Inhibitory receptors sensing HLA-G1 molecules in pregnancy: deciduaassociated natural killer cells express LIR-1 and CD94/NKG2A and acquire p49, an HLA-G1specific receptor. Proc Natl Acad Sci U S A.1999;96:5674-5679.

92. Rajagopalan S, Long EO. A human histocompatibility leukocyte antigen (HLA)-G-specific receptor expressed on all natural killer cells. J Exp Med.1999;189:1093-1100.

93. Yan WH, Fan LA. Residues Met76 and Gln79 in HLA-G alpha1 domain involve in KIR2DL4 recognition. Cell Res.2005;15:176-182.

94. Allan DS, et al. Tetrameric complexes of human histocompatibility leukocyte antigen (HLA)-G bind to peripheral blood myelomonocytic cells. J Exp Med.1999;189:1149-1156. 
95. Boyson JE, et al. Disulfide bond-mediated dimerization of HLA-G on the cell surface. Proc Natl Acad Sci U S A.2002;99:16180-16185.

96. Le Page ME, Goodridge JP, John E, Christiansen FT, Witt CS. Killer Ig-like receptor 2DL4 does not mediate NK cell IFN-gamma responses to soluble HLA-G preparations. J Immunol.2014;192:732-740.

97. Brusilovsky M, et al. Genome-wide siRNA screen reveals a new cellular partner of NK cell receptor KIR2DL4: heparan sulfate directly modulates KIR2DL4-mediated responses. J Immunol.2013;191:5256-5267.

98. Braud VM, et al. HLA-E binds to natural killer cell receptors CD94/NKG2A, B and C. Nature.1998;391:795-799.

99. Borrego F, Ulbrecht M, Weiss EH, Coligan JE, Brooks AG. Recognition of human histocompatibility leukocyte antigen (HLA)-E complexed with HLA class I signal sequencederived peptides by CD94/NKG2 confers protection from natural killer cell-mediated lysis. J Exp Med.1998;187:813-818.

100. Geraghty DE, Stockschleader M, Ishitani A, Hansen JA. Polymorphism at the HLA-E locus predates most HLA-A and -B polymorphism. Human Immunology.1992;33:174-184.

101. Grimsley C, Ober C. Population genetic studies of HLA-E: evidence for selection. Hum Immunol.1997;52:33-40.

102. Joly E, Rouillon V. The orthology of HLA-E and H2-Qa1 is hidden by their concerted evolution with other MHC class I molecules. Biol Direct.2006;1:2.

103. Zeng L, et al. A structural basis for antigen presentation by the MHC class Ib molecule, Qa1b. J Immunol.2012;188:302-310.

104. Phillips JH, Chang C, Mattson J, Gumperz JE, Parham P, Lanier LL. CD94 and a novel associated protein (94AP) form a NK cell receptor involved in the recognition of HLA-A, HLA-B, and HLA-C allotypes. Immunity.1996;5:163-172. 
105. Moretta A, et al. Human natural killer cell receptors for HLA-class I molecules. Evidence that the Kp43 (CD94) molecule functions as receptor for HLA-B alleles. J Exp Med.1994;180:545555.

106. Miller JD, Weber DA, Ibegbu C, Pohl J, Altman JD, Jensen PE. Analysis of HLA-E peptide-binding specificity and contact residues in bound peptide required for recognition by CD94/NKG2. J Immunol.2003;171:1369-1375.

107. Braud VM, Allan DS, Wilson D, McMichael AJ. TAP- and tapasin-dependent HLA-E surface expression correlates with the binding of an MHC class I leader peptide. Curr Biol.1998;8:1-10.

108. Brooks AG, Posch PE, Scorzelli CJ, Borrego F, Coligan JE. NKG2A complexed with CD94 defines a novel inhibitory natural killer cell receptor. J Exp Med.1997;185:795-800.

109. Lazetic S, Chang C, Houchins JP, Lanier LL, Phillips JH. Human natural killer cell receptors involved in MHC class I recognition are disulfide-linked heterodimers of CD94 and NKG2 subunits. J Immunol.1996;157:4741-4745.

110. Carretero M, et al. The CD94 and NKG2-A C-type lectins covalently assemble to form a natural killer cell inhibitory receptor for HLA class I molecules. Eur J Immunol.1997;27:563-567. 111. Houchins JP, Lanier LL, Niemi EC, Phillips JH, Ryan JC. Natural killer cell cytolytic activity is inhibited by NKG2-A and activated by NKG2-C. J Immunol.1997;158:3603-3609. 112. Houchins JP, Yabe T, McSherry C, Bach FH. DNA sequence analysis of NKG2, a family of related cDNA clones encoding type II integral membrane proteins on human natural killer cells. J Exp Med.1991;173:1017-1020.

113. Le Drean E, et al. Inhibition of antigen-induced T cell response and antibody-induced NK cell cytotoxicity by NKG2A: association of NKG2A with SHP-1 and SHP-2 protein-tyrosine phosphatases. Eur J Immunol.1998;28:264-276.

114. Wu J, et al. An activating immunoreceptor complex formed by NKG2D and DAP10. Science.1999;285:730-732. 
115. Bauer S, et al. Activation of NK cells and T cells by NKG2D, a receptor for stress-inducible MICA. Science.1999;285:727-729.

116. Kim DK, Kabat J, Borrego F, Sanni TB, You CH, Coligan JE. Human NKG2F is expressed and can associate with DAP12. Mol Immunol.2004;41:53-62.

117. Orbelyan GA, et al. Human NKG2E is expressed and forms an intracytoplasmic complex with CD94 and DAP12. J Immunol.2014;193:610-616.

118. Bellon T, et al. Triggering of effector functions on a CD8+ T cell clone upon the aggregation of an activatory CD94/kp39 heterodimer. J Immunol.1999;162:3996-4002. 119. Lanier LL, Corliss B, Wu J, Phillips JH. Association of DAP12 with activating CD94/NKG2C NK cell receptors. Immunity.1998;8:693-701.

120. Sullivan LC, et al. The heterodimeric assembly of the CD94-NKG2 receptor family and implications for human leukocyte antigen-E recognition. Immunity.2007;27:900-911.

121. Petrie EJ, et al. CD94-NKG2A recognition of human leukocyte antigen (HLA)-E bound to an HLA class I leader sequence. J Exp Med.2008;205:725-735.

122. Kaiser BK, Pizarro JC, Kerns J, Strong RK. Structural basis for NKG2A/CD94 recognition of HLA-E. Proc Natl Acad Sci U S A.2008;105:6696-6701.

123. O'Callaghan CA, et al. Structural features impose tight peptide binding specificity in the nonclassical MHC molecule HLA-E. Mol Cell.1998;1:531-541.

124. Strong RK, Holmes MA, Li P, Braun L, Lee N, Geraghty DE. HLA-E allelic variants. Correlating differential expression, peptide affinities, crystal structures, and thermal stabilities. J Biol Chem.2003;278:5082-5090.

125. Hoare HL, et al. Subtle changes in peptide conformation profoundly affect recognition of the non-classical MHC class I molecule HLA-E by the CD94-NKG2 natural killer cell receptors. J Mol Biol.2008;377:1297-1303.

126. Hoare HL, et al. Structural basis for a major histocompatibility complex class Ib-restricted T cell response. Nat Immunol.2006;7:256-264. 
127. Vales-Gomez M, Reyburn HT, Erskine RA, Lopez-Botet M, Strominger JL. Kinetics and peptide dependency of the binding of the inhibitory NK receptor CD94/NKG2-A and the activating receptor CD94/NKG2-C to HLA-E. EMBO J.1999;18:4250-4260.

128. Kaiser BK, Barahmand-Pour F, Paulsene W, Medley S, Geraghty DE, Strong RK. Interactions between NKG2x immunoreceptors and HLA-E ligands display overlapping affinities and thermodynamics. J Immunol.2005;174:2878-2884.

129. Vales-Gomez M, Reyburn HT, Mandelboim M, Strominger JL. Kinetics of interaction of HLA-C ligands with natural killer cell inhibitory receptors. Immunity.1998;9:337-344.

130. Heatley SL, et al. Polymorphism in human cytomegalovirus UL40 impacts on recognition of human leukocyte antigen-E (HLA-E) by natural killer cells. J Biol Chem.2013;288:8679-8690.

131. Tomasec P, et al. Surface expression of HLA-E, an inhibitor of natural killer cells, enhanced by human cytomegalovirus gpUL40. Science.2000;287:1031.

132. Djaoud Z, et al. Amplified NKG2C+ NK cells in cytomegalovirus (CMV) infection preferentially express killer cell Ig-like receptor 2DL: functional impact in controlling CMVinfected dendritic cells. J Immunol.2013;191:2708-2716.

133. Guma M, Angulo A, Vilches C, Gomez-Lozano N, Malats N, Lopez-Botet M. Imprint of human cytomegalovirus infection on the NK cell receptor repertoire. Blood.2004;104:3664-3671.

134. Guma M, et al. Expansion of CD94/NKG2C+ NK cells in response to human cytomegalovirus-infected fibroblasts. Blood.2006;107:3624-3631.

135. Rolle A, et al. IL-12-producing monocytes and HLA-E control HCMV-driven NKG2C+ NK cell expansion. J Clin Invest.2014;124:5305-5316.

136. Lopez-Verges S, et al. Expansion of a unique CD57(+)NKG2Chi natural killer cell subset during acute human cytomegalovirus infection. Proc Natl Acad Sci U S A.2011;108:14725-14732. 137. Foley B, et al. Human cytomegalovirus (CMV)-induced memory-like NKG2C(+) NK cells are transplantable and expand in vivo in response to recipient CMV antigen. J Immunol.2012;189:5082-5088. 
138. Gendzekhadze K, et al. Co-evolution of KIR2DL3 with HLA-C in a human population retaining minimal essential diversity of KIR and HLA class I ligands. Proc Natl Acad Sci U S A.2009;106:18692-18697. 
Table 1: Common HLA residues shared as KIR contacts

\begin{tabular}{|c|c|c|c|c|c|c|c|}
\hline \multicolumn{4}{|c|}{ HLA } & \multicolumn{4}{|c|}{ KIR } \\
\hline $\mathrm{C}^{\mathrm{a}}$ & C1 & A11 & Bw4 & "KIR2DL1 & "KIR2DL2 & "KIR2DS2 & "KIR3DL1 \\
\hline & & & Gly16 & & & & $\begin{array}{l}\text { Phe9 } \\
\text { Ser11 } \\
\text { His29 } \\
\text { Phe34 }\end{array}$ \\
\hline & & & Arg17 & & & & Phe9 \\
\hline & & & Gly18 & & & & Phe9 \\
\hline Arg69 & Arg69 & & & Arg68 & $\begin{array}{l}\text { Glu21 } \\
\text { Met70 }\end{array}$ & & \\
\hline Gln72 & Gln72 & Gln72 & Gln72 & Arg68 & $\begin{array}{l}\text { Asp72 } \\
\text { Met70 }\end{array}$ & & Met165 \\
\hline Arg75 & Arg75 & Arg75 & & Phe45 & Phe45 & $\begin{array}{l}\text { Asp72 } \\
\text { Met70 }\end{array}$ & \\
\hline Val76 & Val76 & Val76 & Glu76 & $\begin{array}{l}\text { Phe45 } \\
\text { Met70 } \\
\text { Asp72 }\end{array}$ & Phe45 & $\begin{array}{l}\text { Met70 } \\
\text { Gln71 }\end{array}$ & Ala167 \\
\hline Arg79 & Arg79 & Gly79 & Arg79 & Phe45 & $\begin{array}{l}\text { Lys44 } \\
\text { Phe45 }\end{array}$ & Tyr45 & $\begin{array}{l}\text { Gly138 } \\
\text { Ser140 }\end{array}$ \\
\hline Lys80 & Asn80 & Thr80 & Ile80 & $\begin{array}{l}\text { Met44 } \\
\text { Ser184 } \\
\text { Glu187 } \\
\text { Gln71 }\end{array}$ & $\begin{array}{l}\text { Lys44 } \\
\text { Ser184 }\end{array}$ & Tyr45 & Leu166 \\
\hline & & & Arg83 & & & & His278 \\
\hline Tyr84 & Tyr84 & & Tyr84 & Asp183 & Asp183 & & His278 \\
\hline & & & Glu89 & & & & Trp13 \\
\hline & & Ile142 & Ile142 & & & Asp183 & His278 \\
\hline Arg145 & Arg145 & Arg145 & Arg145 & $\begin{array}{l}\text { Ser133 } \\
\text { Asp135 }\end{array}$ & $\begin{array}{l}\text { Ser133 } \\
\text { Asp135 }\end{array}$ & $\begin{array}{l}\text { Ser133 } \\
\text { Asp135 } \\
\text { Phe181 }\end{array}$ & $\begin{array}{l}\text { Ser228 } \\
\text { Asp230 } \\
\text { Phe276 }\end{array}$ \\
\hline Lys146 & Lys146 & Lys146 & Lys146 & $\begin{array}{l}\text { Tyr105 } \\
\text { Phe181 } \\
\text { Asp183 } \\
\text { Ser184 }\end{array}$ & $\begin{array}{l}\text { Tyr105 } \\
\text { Phe181 } \\
\text { Asp183 } \\
\text { Ser184 }\end{array}$ & $\begin{array}{l}\text { Tyr105 } \\
\text { Phe181 } \\
\text { Ser184 }\end{array}$ & $\begin{array}{l}\text { Tyr200 } \\
\text { Phe276 } \\
\text { Ser279 } \\
\text { Glu282 }\end{array}$ \\
\hline Ala149 & Ala149 & Ala149 & Ala149 & $\begin{array}{l}\text { Tyr105 } \\
\text { Glu106 } \\
\text { Ser132 }\end{array}$ & $\begin{array}{l}\text { Tyr105 } \\
\text { Glu106 } \\
\text { Ser132 }\end{array}$ & $\begin{array}{l}\text { Tyr105 } \\
\text { Glu106 } \\
\text { Ser132 }\end{array}$ & $\begin{array}{l}\text { Tyr200 } \\
\text { Glu201 } \\
\text { Ser227 }\end{array}$ \\
\hline Ala150 & Ala150 & & Ala150 & Leu104 & Leu104 & & Tyr200 \\
\hline Arg151 & Arg151 & His151 & Arg151 & Glu106 & Glu106 & Glu106 & Glu201 \\
\hline & peptide & & & & & & \\
\hline & Leu7 & & & & $\begin{array}{l}\text { Leu104 } \\
\text { Tyr105 }\end{array}$ & & \\
\hline & Ala8 & & Ser8 & & Gln71 & & Leu166 \\
\hline & $\beta_{2} \mathrm{~m}$ & & & & & & \\
\hline & & & Glu36 & & & & His32 \\
\hline
\end{tabular}

a. C2/KIR2DL1 contacts based on (30); C1/KIR2DL2 on (29); A11/KIR2DS2 on (31) and Bw4/KIR3DL1 on (33) but have been refined to $3.8 \AA$. Salt bridges are coloured red; H-bonds blue. Specificity-defining HLA residues are in bold. 
Table 2: Polymorphic residues among KIR3D molecules

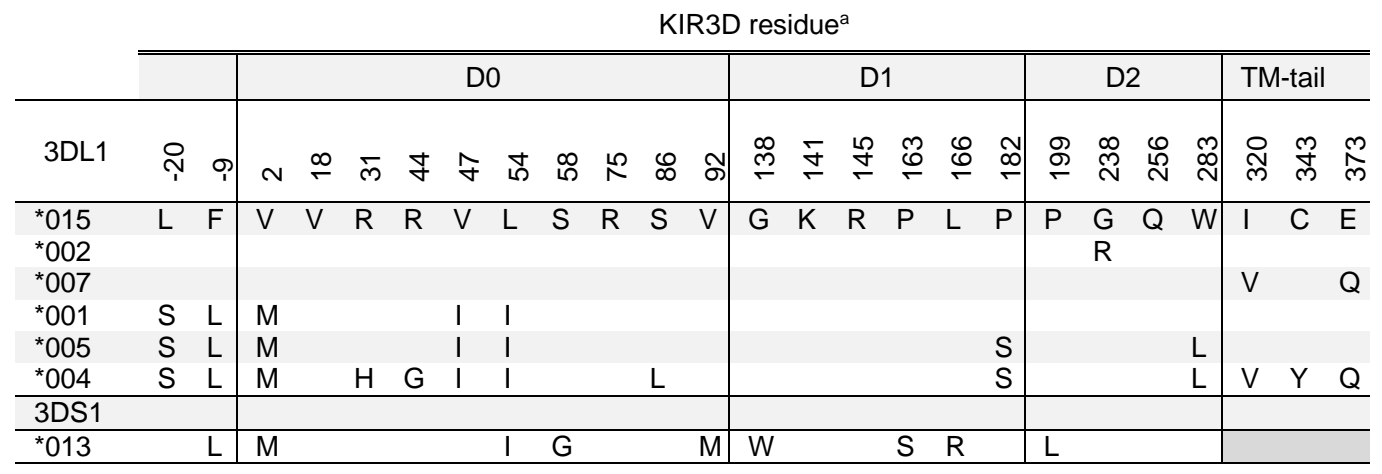

a. Table adapted from (54). Note that the list of KIR3D residues displaying polymorphism is not exhaustive. 
Figure 1

\section{TARGET CELL}

HLA-E HLA-C2 HLA-C1 HLA-Bw4 HLA-A3/11 (HLA-C2)

sHLA-G HLA-C2 HLA-A11 HLA-A11 HLA-Bw4? HLA-E (HLA-C1/2)
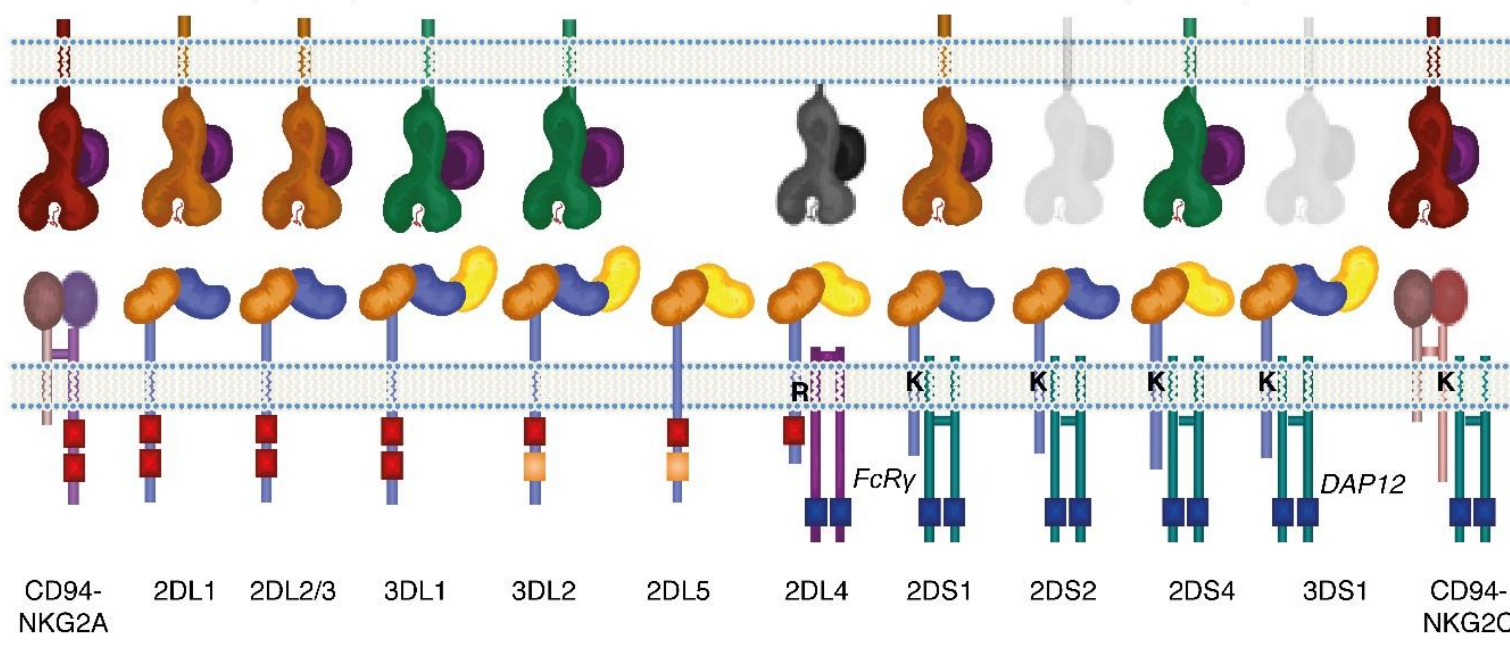

Inhibitory receptors

Activating receptors

NK CELL

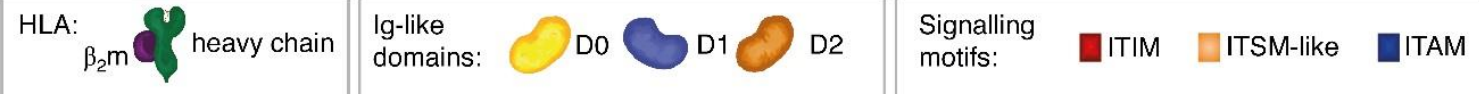


Figure 2

A

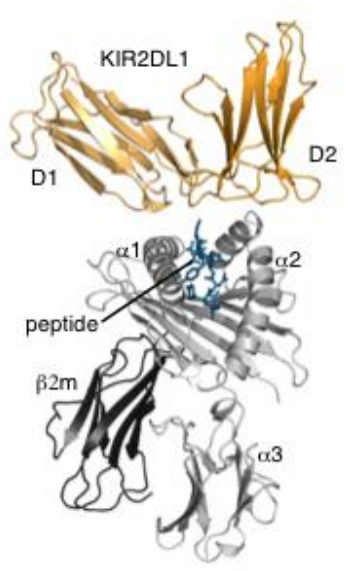

B

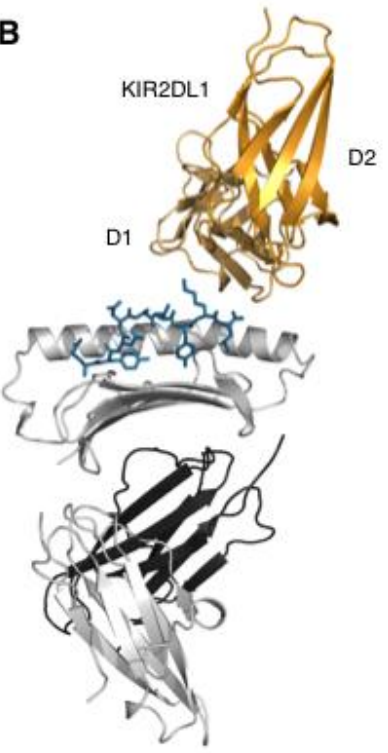

C
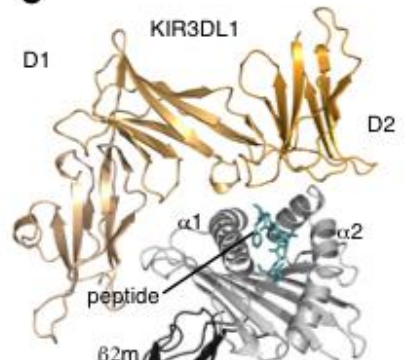

DO

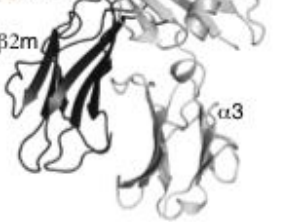

D

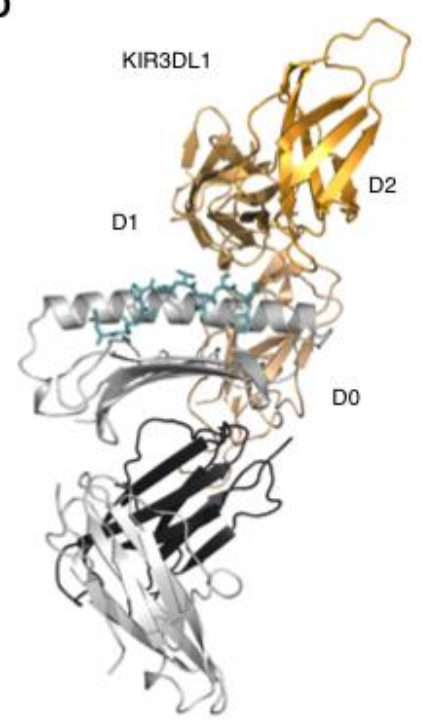

E

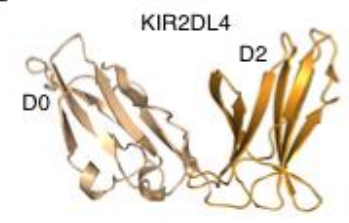

F

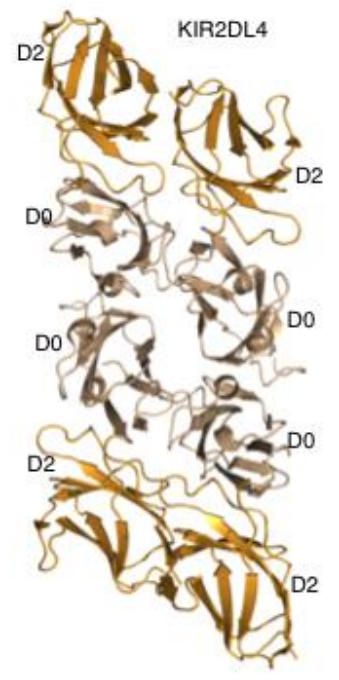

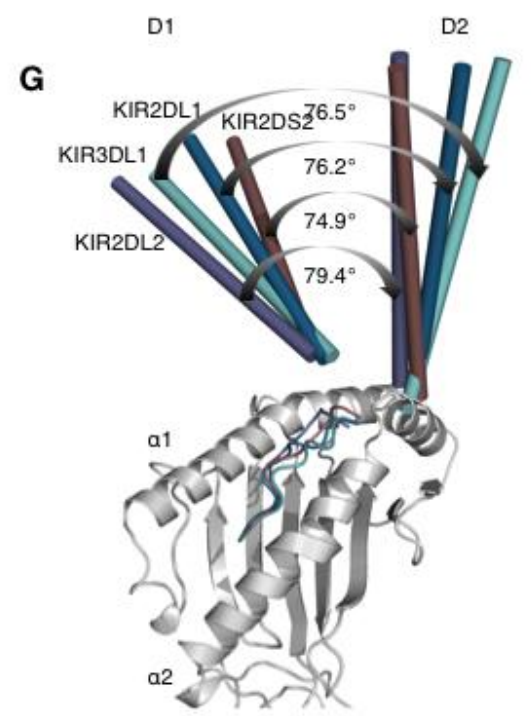

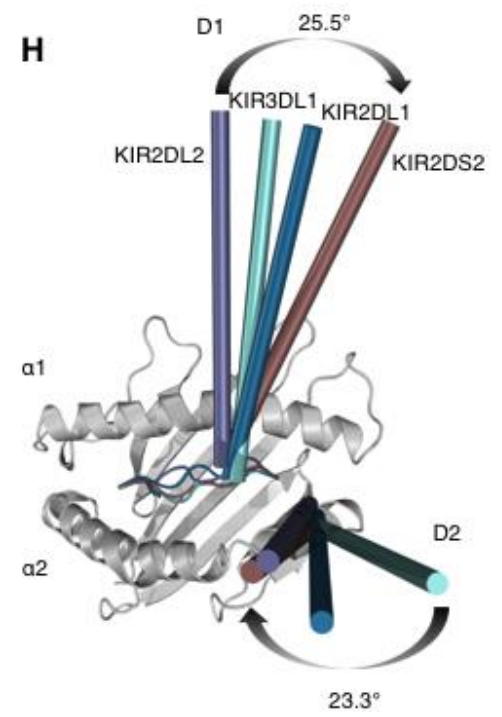


Figure 3

A.

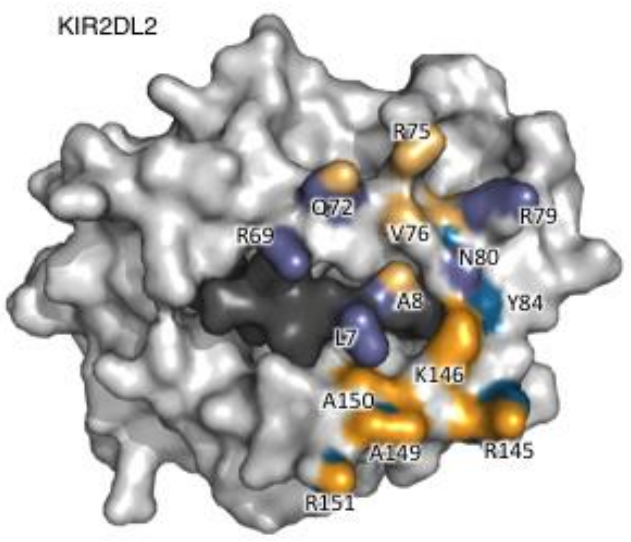

c.

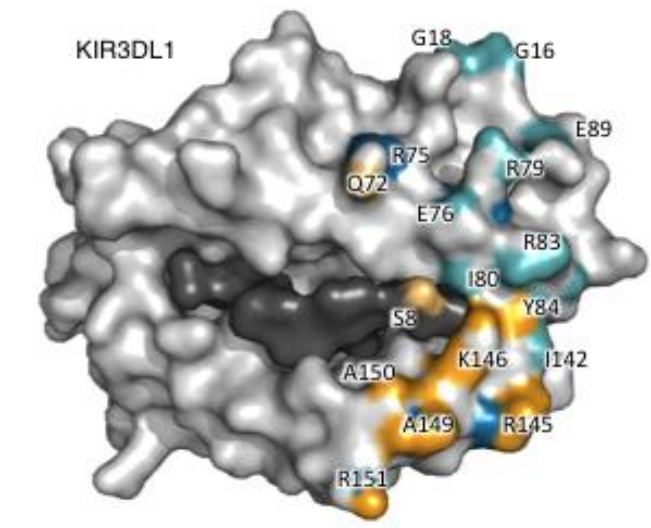

KIR2DL1 Contact

KIR2DL2 Contact

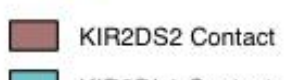

$\square$ KIR3DL1 Contact
B.

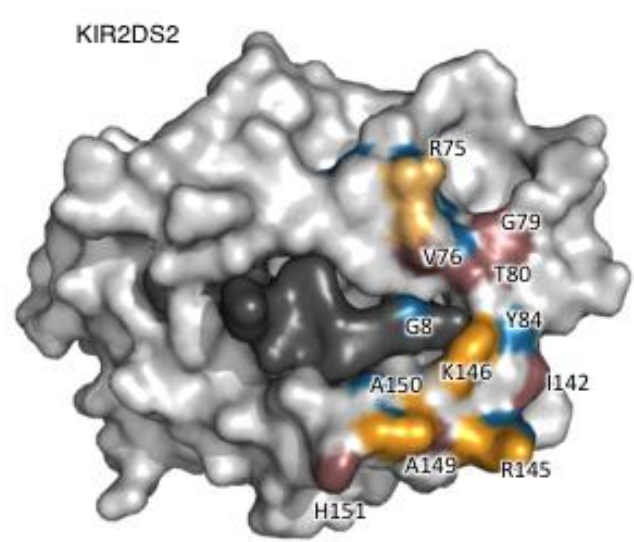

D.

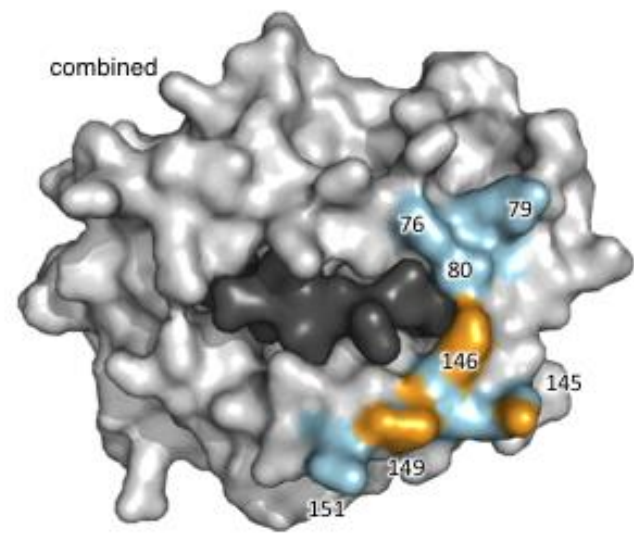

Conserved Contact Residue

\section{Conserved Di Contact}

Conserved D2 Contact 
Figure 4
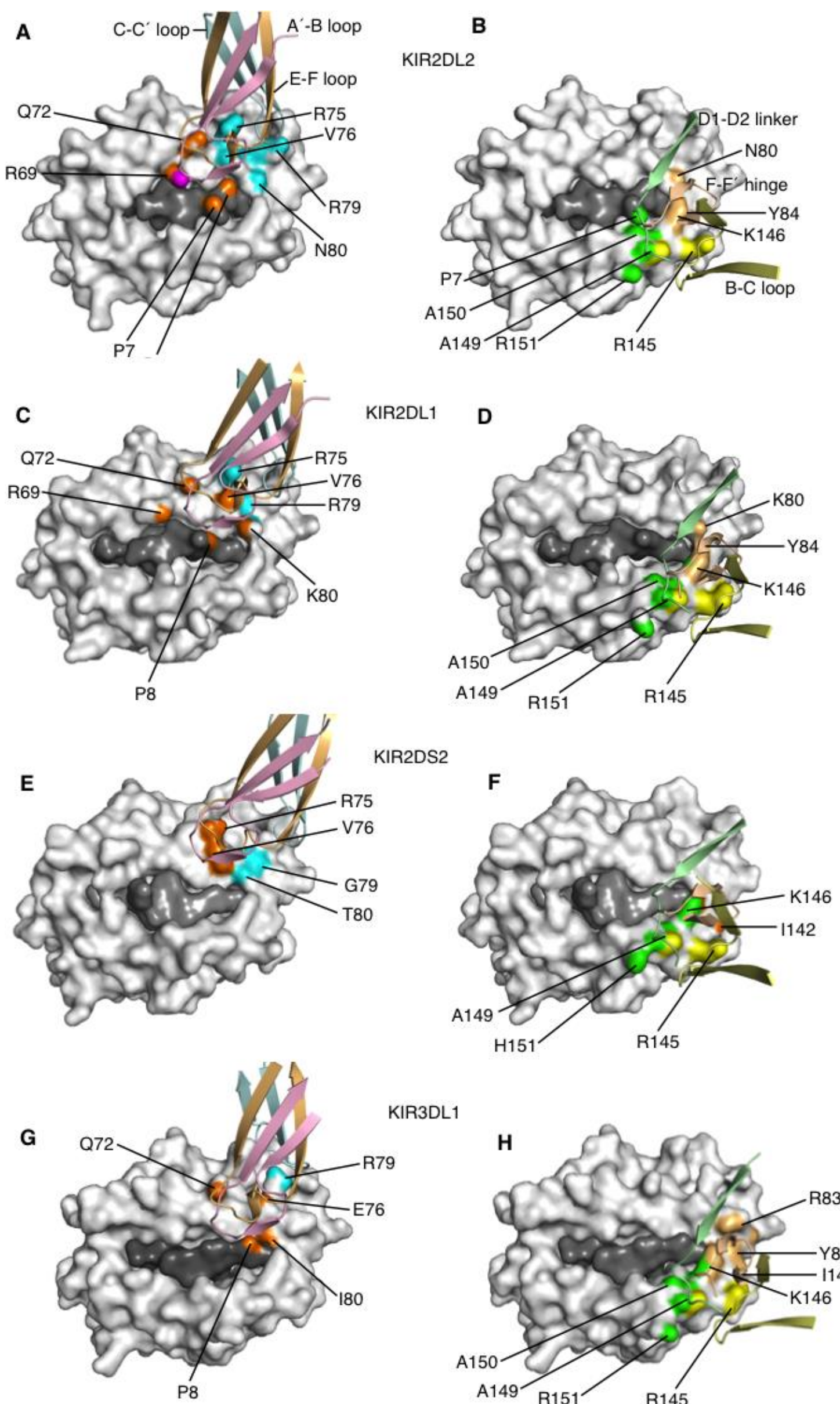

KIR3DL1

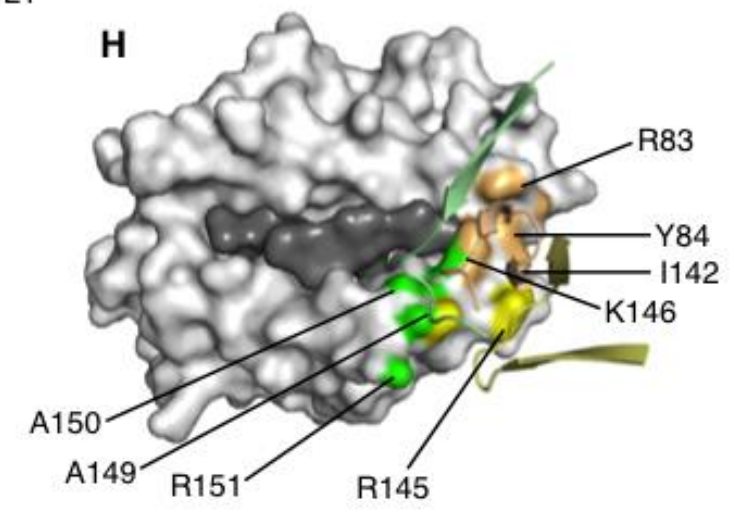


Figure 5
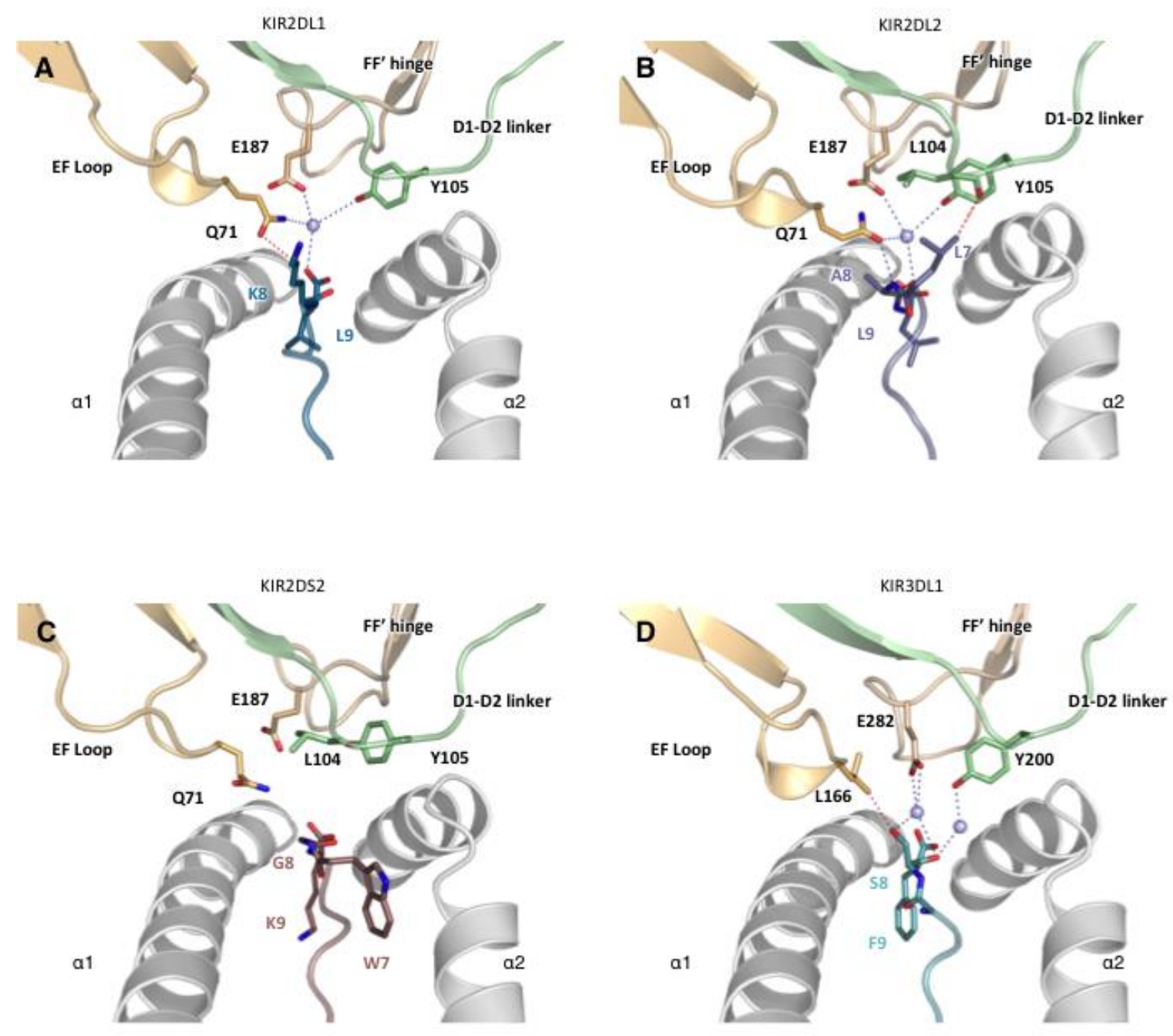
Figure 6

A

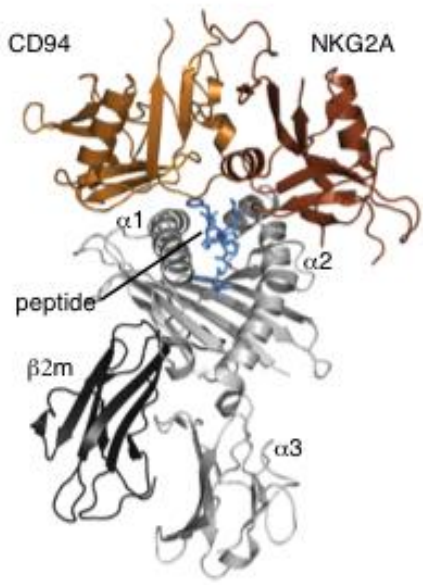

B

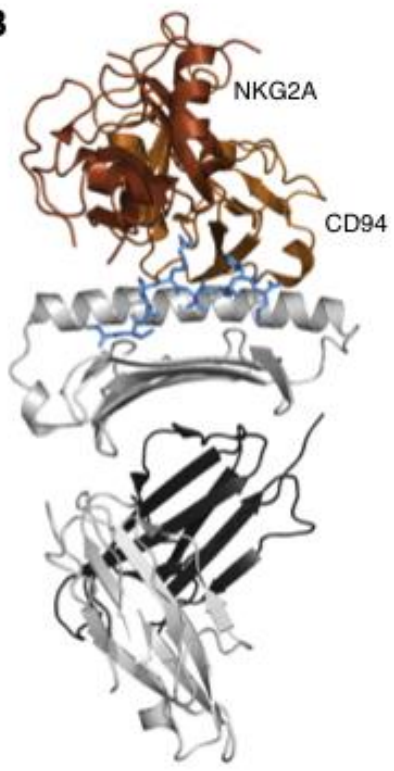

C

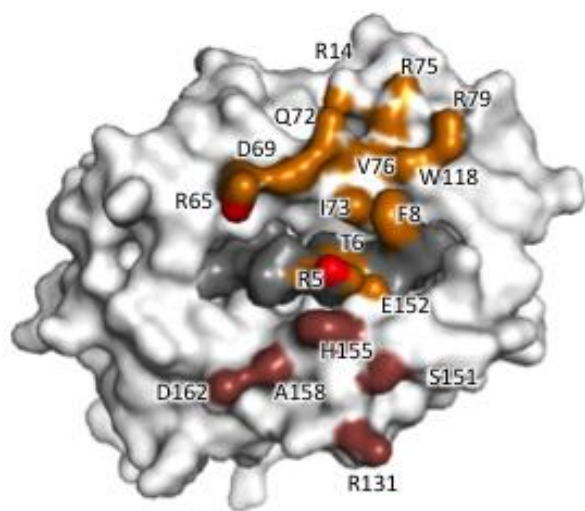

D

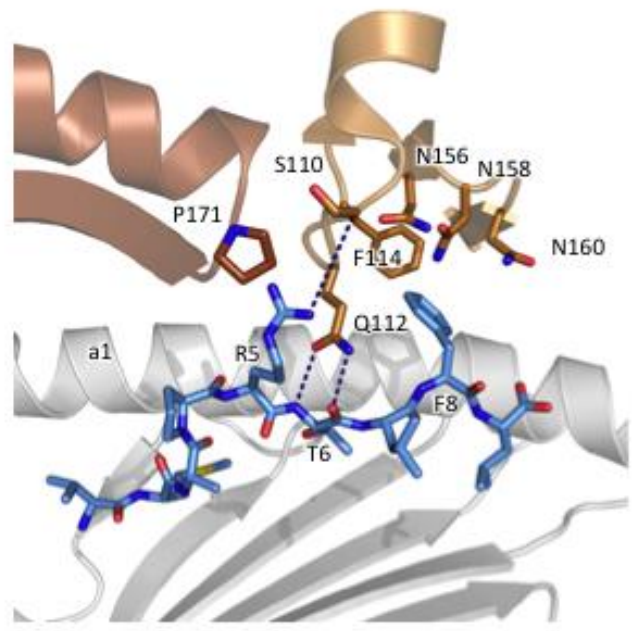

